\title{
Sagreriana Parva
}

\author{
Marià Carbonell i Buades \\ Universitat Autònoma de Barcelona \\ mariano.carbonell@uab.cat
}

\section{RESUM}

Una nova lectura del plet instat per Guillem Sagrera contra el Col-legi de Mercaders de Mallorca permet formular noves hipòtesis sobre algunes solucions constructives de la Llotja de Palma i sobre l'origen de l'infortuni financer que va patir. D'altra banda, l'article ofereix una revisió de les dades genealògiques conegudes de l'arquitecte $\mathrm{i}$ aporta algunes novetats sobre artistes $\mathrm{i}$ artesans contemporanis del mallorquí que treballen a Nàpols.

Paraules clau:

Sagrera, Gomar, arquitectura, Mallorca, Nàpols, Llotja, gòtic.

\section{Abstract}

\section{Sagreriana Parva}

A new reading of the lawsuit made by Guillem Sagrera against the Guild of Merchants of Majorca allows us to formulate new hypotheses on some constructive solutions of the Llotja de Palma and on the origin of the architect's financial misfortune. On the other hand, this article revises the known genealogical data of the architect and contributes some new information about Majorcan artists and contemporary craftsman who work in Naples.

Key words:

Sagrera, Gomar, architecture, Majorca, Naples, Llotja, gothic. 

- Atlots, on anau?
- Vos pensau que ho sabem? A acanar món. A engolir vent.
A prendre sol. A beure primavera!

A Jaume Cañellas Mut, in memoriam
1. Gabriel Llompart, «Sagreriana minora», BSAL, 39 (1983), p. 407-434. Tractant-se d'un homenatge implícit, confio en l'absolució del P. Llompart pel títol del meu article, bé que de minimis non curat praetor

2. Gabriel Alomar, Guillem Sagrera y la arquitectura gótica del siglo $\mathrm{XV}$, Barcelona, 1970.

3. Gabriel Llompart, «Miscelánea de arquitectura y plástica sacra mallorquina (siglos XIII-XVI)», Analecta Sacra Tarraconensia XLVI (1973), p. 83-114.

4. Ramon Rosselló Vaquer, Mestre Guillem Sagrera, Felanitx, 1976.

5. Maria Rosa Manote, «L'escultura gòtica catalana de la primera meitat del segle xv a la Corona d'Aragó: Pere Joan i Guillem Sagrera», tesi doctoral (inèdita), Universitat de Barcelona, 1994.

6. Maria Rosa Manote, «El contrato y el pleito de la Lonja entre Guillem Sagrera y el Colegio de mercaderes de Ciutat de Mallorca», dins Xavier BARRAL (a cura de), Artistes, artisans et production artistique au Moyen Age. I. Les hommes, París, 1986, p. 577-588; «Guillem Sagrera i Pere Joan, dos artistes catalans al servei d'Alfons el Magnànim a la cort de Nàpols», La Corona d'Aragona ai tempi di Alfonso il Magnanimo, Actes del XVI Congrés Internacional d'Història de la Coron d'Aragó (Nàpols, 1997), Nàpols, 2000, vol. 2, p. 1729-1743.

7. Joana Maria Palou, Guillem Sagrera, Palma, 1985.

8. Amadeo SERra, «È cosa catalana: la Gran Sala de Castel Nuovo en el contexto mediterráneo", $A n-$ nali di Architettura, 12 (2000), p. 7-16; «La Gran Sala de Castelnuovo en el contexto mediterráneo", dins La Corona d'Aragona ai tempi di Alfonso il Magnanimo,

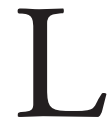

'any 1983, Gabriel Llompart publicava un article titulat «Sagreriana Minora», breu d'extensió, però també d'una envejable densitat documental, ja que presentava ni més ni manco que quinze documents inèdits sobre l'arquitecte Guillem Sagrera i la seva família -en sentit generós, ja que això també inclou alguns seguidors professionals del mestre $-{ }^{1}$. Un dels mèrits d'aquell text és el d'haver insistit en la figura de l'arquitecte felanitxer, llavors molt negligida per la historiografia artística. De fet, des de l'admirable monografia de Gabriel Alomar (I970)², no s'havia afegit res més a la bibliografia sagreriana, llevat de les notes documentals aportades pel mateix Gabriel Llompart (1973) ${ }^{3}$ i Ramon Rosselló Vaquer $(\mathrm{I} 976)^{4}$. Després, Sagrera ha estat objecte de treballs de recerca més o manco ambiciosos, encara que fragmentaris. A més de la tesi de doctorat de Maria Rosa Manote sobre l'obra escultòrica de Pere Joan i Guillem Sagrera (1994) ${ }^{5}$, encara inèdita - sols n'ha aprofitat una minsa part en dos articles, dels anys 1986 i $2000^{6}-\mathrm{i}$ de la síntesi divulgativa de Joana Maria Palou (1985) ${ }^{7}$, caldrà fer memòria de pocs, però prou importants, articles dedicats a l'activitat constructiva del mallorquí, escrits per Amadeo Serra (2000, dues versions del mateix text) ${ }^{8}$ i Joan Domenge (200I, 2003, 2007) $)^{9}$, a més de la monografia dedicada a la Llotja de Palma (2003), coordinada per F. Climent, amb els principals capítols redactats per Catalina Cantarellas i T. Sabater ${ }^{10}$. El panorama serà incomplet si no hi afegim alguns treballs de caràcter documental, més o manco específics i d'interès desigual, com ara els de Ramon Rosselló Vaquer (1984, I997) ${ }^{11}$, Maria Barceló (1993, 2000, 200I, 2003) $)^{12}$, Onofre Vaquer (2000) ${ }^{13}$, Jaume Sastre $(2007)^{14}$ i el mateix P. Gabriel Llompart (1993, I999) ${ }^{15}$.

Finalment, doncs, encara que no puguem disposar d'un llibre monogràfic que substitueixi el de l'arquitecte Alomar, el ritme historiogràfic s'ha ajustat a la transcendència de l'obra sagreriana. Això no obstant, en el futur caldrà envestir tasques complexes, tant a partir de l'examen directe de l'obra, com insistint en la recerca d'arxiu. Per exemple, és necessari depurar el catàleg d'escultura, inflat amb peces d'escassa qualitat, que s'allunyen dels estàndards irrefutables del mestre, i a la vegada amb altres de magnífiques, com ara la Mare de Déu del Mirador, que, estilísticament, no s'avenen amb l'obra documentada ${ }^{16}$. A més, convé de temptar una millora del relat biogràfic, aclarir la composició del grup de col-laboradors, incrementar el corpus arquitectònic, etc. Encara, a manca d'informació documental satisfaent, pot resultar útil formular hipòtesis noves. Posem per cas: a quina obra (coberta de la nau?, capelles del primer tram dels peus?, portal d'accés a la Cathedra Pacis?) obeïen les cent setanta lliures i escaig que una sentència de la cúria de l'abat de la Real del 6 de setembre de 1453 compel-lia els obrers de l'església de Santa Eulàlia a pagar a Guillem Sagrera, dada publicada que ha passat desapercebuda a la crítica? ${ }^{17}$. O bé, quina fou la intervenció exacta - que, tanmateix, s'endevina modesta - de l'arquitecte - i, més tard, de Bartomeu i Guillem Vilasclar - en la construcció de l'antic campanar de la parròquia de Llucmajor, un tema que tampoc no ha suscitat cap interès? ${ }^{18}$. I no fóra raonable proposar una alternativa a la presumptiva participació del mestre en la construcció de la capella de la Passió, ara de sant Francesc, de la parròquia de Felanitx, que presenta una barroera decoració escultòrica, impròpia de l'autor del sant Pere del portal marítim de la seu? En aquest cas, el còmode recurs al «taller» no és prou convincent. En canvi, no és inconcebible sostenir una hipòtesi alternativa: que la capella de pedra que va bastir Sagrera gràcies a 
una llicència episcopal de l'any i442, «en el lloc convingut» amb els jurats, fos l'antiga esglesieta del puig de Sant Salvador, que, fins al segle XviII, també tenia l'altar major dedicat a la Passio Imaginis - llavors s'identificaven totes dues advocacions, que se celebraven el 9 de novembre. Així també es justificaria millor l'encàrrec del nou retaule de pedra (I448-I453) a Huguet Barxa, un estret colllaborador de l'arquitecte; a més, tant la capella encarregada a Sagrera com el retaule atribuït a Barxa foren subvencionats per la família Sabet ${ }^{19}$. Pel que fa a Barxa, el trobem relacionat amb Sagrera almanco des del I 428 , quan actua de testimoni en la concessió d'un préstec de tres-centes vint-i-quatre lliures de l'arquitecte a favor d'Antoni Comelles; el crèdit fou cancel-lat un any més tard ${ }^{20}$.

Algunes obres s'han d'excloure del catàleg per sentit comú: hi ha qui no ha sabut interpretar l'allusió documental a treballs fets per a la Universitat, que obligaren a paralitzar sis mesos, de setembre del I435 a febrer del I436, la fàbrica de la Llotja. Naturalment, no es tracta de l'Estudi General, sinó de la institució de govern local: l'única obra segura que Sagrera va bastir per encàrrec dels jurats va ser un dels ponts de la riera («per fer l'arcada a la Riera per manament del Governador e Jurats del Regne»), a més de les obres efectuades entre I423 $\mathrm{i}$ I424 al moll, arran de la guerra amb els genovesos, per les quals encara li devien doblers l'any $\mathrm{I} 449^{21}$. Per contra, hi ha unes altres obres que permetran explicar millor l'activitat del mestre com a tracista i empresari de la construcció. Això s'infereix d'un contracte datat el i 8 de febrer de I440, publicat ja fa temps pel pare Gabriel Llompart ${ }^{22}$, en virtut

Actes del XVI Congrés Internacional d'Història de la Corona d'Aragó (Nàpols, 1997), Nàpols, 2000, vol. 2, p. 1787-1799.

9. El més complet estat de la qüestió el devem a Joan Domen$\mathrm{GE}$, "Guillem Sagrera. Alcance y lagunas de la historiografía sagreriana», a E. Mira i A. ZARAGOzÁ (comissaris), Una arquitectura gótica mediterránea, 2 vols., València, 2003, vol. II, 115-132. Ara com ara, la revisió més exhaustiva i novadora de l'obra sagreriana també és la de Joan Domenge, "Guillem Sagrera», dins Emanula Garofalo i Marco Rosario Nobile (coord.), Gli ultimi independenti. Maestri e Architetti nel Mediterraneo (XV-XVI secolo), Palerm, 2008, p. 59-93. Del mateix autor, vegeu a més «Guillem Sagrera, maître d'oeuvre de la cathédrale de Majorque. Aspects métriques et économiques du travail de la pierre (1422-1446)», Histoire $\&$ Mesure, XVI-3/4 (2001), p. 373-403 (es pot consultar per Internet).

10. Catalina Cantarellas, «For-

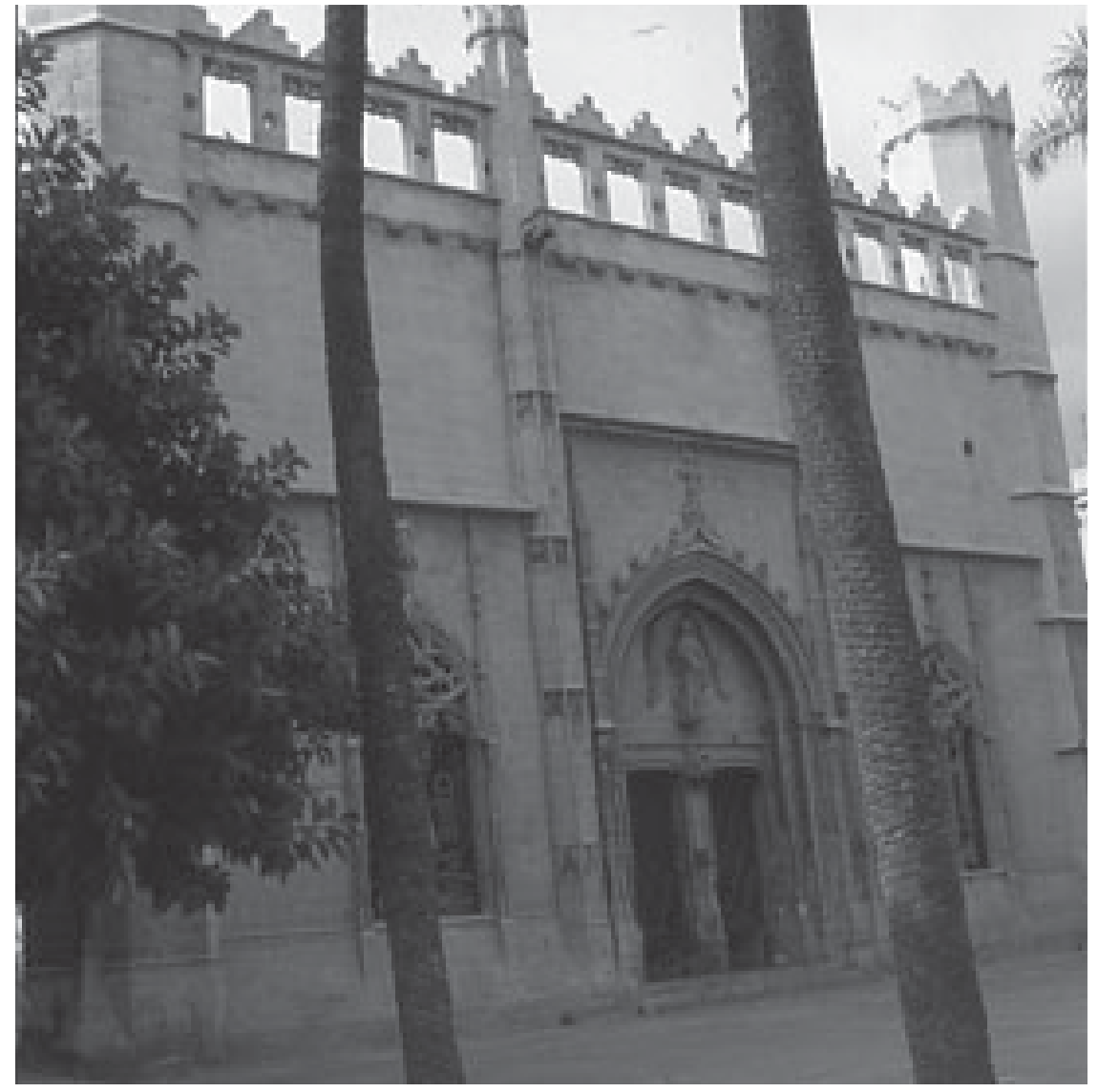

Figura 1.

Guillem Sagrera i altres: Llotja de Palma, façana principal. Foto de l'autor.

(Nàpols, 1997), Nàpols, 2000, vol. 2, p. 1201-1219.

14. Jaume SAStre, La Seu de Mallorca (1390-1430). La prelatura del bisbe Lluis de Prades $i$ d'Arenós, Palma, 2007.

15. Gabriel

LLOMPART,

tuna crítica e historiogràfica», dins F. Climent (coord.), La Lonja de Palma, Palma, 2003, p. 1-21.

11. Ramon Rosselló VAQuer, La pedra "de Santanyí de Felanitx, Fires i festes de Sant Agustí, Felanitx, 1984; Noticiari felanitxer, 1228-1599, Felanitx, 1997.

12. Maria Barceló, «Notes sobre els Vilasclar, picapedrers", BSAL, 49 (1993), p. 127-140; «Notes sobre alguns picapedrers a la Mallorca tardomedieval», BSAL, 56 (2000), p. $103-$

116; «Semblança de Guillem Vilasclar", I Jornades d'Estudis Locals de Felanitx, Felanitx, 2001, p. 38-48; «Nous documents sobre l'art de la construcció», BSAL, 59 (2003), 221-248

13. Onofre Vaquer, "Comerç entre Mallorca i Nàpols després de la conquesta de 1443», dins La Corona d'Aragona ai tempi di Alfonso il Magnanimo, Actes del XVI Congrés Internacional d'Història de la Corona d'Aragó
«Maestros albañiles y escultores en el Medievo mallorquín", BSAL, 49 (1993), p. 249-272; Miscelánea documental de pintura y picapedrería medieval mallorquina, Palma, 1999.

16. Carmen Morte, «Esplendors i conflictes: els Trastàmar (1412-1516)», dins La Corona d'Aragó. El poder $i$ la imatge de l'edat mitjana a l'edat modern (segles XII-XVIII), catàleg de l'exposició, València, 2006, p. 186 245, en particular p. 193. «L Mare de Déu del Mirador, de la catedral de Palma, tradicionalment atribuilda a Sagrera, segons l'opinió dels professors Joaquim Garriga i Marià Carbonell pot ser una obra italiana amb ecos ghibertians». Naturalment, aquesta hipòtesi exigeix un al-legat minuciós, però ara s'esmenta sols pe deixar-ne constància. En realitat, la idea és mèrit de J. Garriga, però m'hi vaig adherir tot d'una. En canvi, hi notava un eco de Giovanni Pisano el professor Harold E. Wethey, «Guillermo Sagrera», The Art Bulletin XXI/1 (1939), p. 44-60
17. Ramon Rosselló Vaouer, Cronicó felanitxer. Apèndix. S. XIII-XVI, Felanitx, 1986, p. 21 Per a la cronologia constructiva de l'església de Santa Eulàlia, és encara important l'obra de Marcel Durliat, L'art en el Regne de Mallorca, Palma, 1964, en particular p. 106-114 (hi ha reedició del 1989). Tanmateix, ara disposem de la memòria històrica sobre l'edifici que va redactar Joan Miquel Sureda fa un centenar d'anys. Vegeu Soledad Quiroga (a cura de), La reform de l'església de Santa Eulàlia de Palma (1889-1912). La "Memoria sobre las obras" del Marquès de Vivot, Palma, 2008. La Cathedra Pacis era el recinte os es posava en pràctica el dret d'asil. $\mathrm{Va}$ desaparèixer al segle xvIII, però en resta el portal d'accés, embegut en el rerecor del temple. Adopta forma d'arc carpanell rebaixat, emmarcat per fines agulles i coronat amb fronda, floró i una delicada arqueria calada de petites i elegants arcades bífores. Suporta fàcilment la comparació amb la porta de l'Almoina de la seu i amb el portal oriental de la Llotja, encara que també pot ser de cronologia anterior.

18. Bartomeu Font OBRAdor, La villa de Lluchmayor durante el siglo $\mathrm{XV}$, Llucmajor, 1969 , p. 18 : «doní [quinze sous] e nen Sagrere per vanir así a dar consell on hom poguer estar lo seny». Però l'any
1469 Guillem Vilasclar cobrava deu sous «per una venguda que lo dit mestre ha feta a la parròquia per veure en quin loch se faria lo cloquer». Mentrestant, l'any 1424 Bartomeu Vilasclar havia cobrat vint sous i escaig "per jornals que fiu en lo cloquer».

19. Pensa exactament el contrari, és a dir, que el retaule atribuït a Huguet Barxa procedeix de la capella de la mateixa advocació de l'església parroquial Pere XAMENA, «Les successives esglésies de Sant Salvador», Estudis Baleàrics, 62/63 (1998-1999), p. 81-86. En qualsevol cas, les escultures d'aquesta capella no són dignes del catàleg de Guillem Sagrera. L'actual església de Sant Salvador data del segle xviII.

20. Gabriel Llompart, «Més precisions sobre Huguet Barxa, imaginaire medieval», Estudis Baleàrics, 62/63 (1998-1999), p. 53-59. La notícia prové de l'Arxiu G. Llabrés i li fou notificada per Maria Rosa Manote. En aquest article, el pare Llompart publica l'inventari postmortem de Barxa, datat l'any 1462.

21. Ramon Rosselló VaQuer, Cronicó..., 1986, p. 19

22. Gabriel Llompart, «Huguet Barxa, autor del retablo del «Passio Imaginis» de Felanitx (Mallorca)", Archivo Español de Arte, 
50 (1977), p. 328-335 (reproduit a Gabriel Llompart, Entre la Historia del arte y el folklore. Folklore de Mallorca, Folklore de Europa, Palma, 1984, p. 267 274 , n. 9). Recentment, ha estat divulgat, sense adonar-se'n de la publicació precedent, per Maria BARCEló, "Nous documents sobre l'art de la construcció», BSAL, 59 (2003), p. 221-248, doc. 1. En un contracte del 1451 (document 4 d'aquest últim article), hi apareix Bartomeu Pons, guixer, que podria ser el lapiscida homònim, soci d'en Barxa. Gràcies a la mateixa M. Barceló, sabem que Guillem Vilasclar, picapedrer d'ofici, podia treballar de guixer, sempre que pagués la taxa a la confraria corresponent. L'any 1460 , el mateix Bartomeu Pons es comprometia a proporcionar pedra de galga per a la capella de Sant Abdó Sant Senén del convent del Carme de Palma (Maria Barceló, «Nous documents sobre l'art de la construcció. II», BSAL, 63 (2007), p. 209-226, doc. II). En tot cas, ara podem assegurar que el picapedrer Bartomeu Pons era oriünd d'Alaró i que tenia un germà, Guillem, que practicava el mateix ofici. D'aquest últim, n'he localitzat un codicil, en què fa un llegat al germà, encara que nomena hereu un fill del picapedrer Jaume Servera, o Cervera (de qui va ser soci l'any 1434 en les obres de l'església de Sant Jaume i, segurament, cunyat), ncloses unes cases a la pedrera de Rafalbeig (ARM, Protocols, A-75; 1446, 1 d'octubre). En una acta de venda, consta que Jaume Servera era «lapiscida» de Ciutat de Mallorca, però que un seu fill homònim residia també a Alaró (ARM, Protocols, 4791, f. 79 v.; 1457, 6 de maig). A més, ja el 25 de febrer de 1444, Guillem Pons i Jaume Cervera venien vuit lliures censals sobre una peça de terra situada a Alaró (ARM, Protocols, A-89). L'any 1447 , Cervera i Pons, juntament amb Jaume Mates, eren els únics picapedrers insaculats per a l'elecció de la juraria, d'acord amb el nou règim aprovat pel rei Alfons (ACA, Cancelleria, Reg. 2699, f. 98 v.; 1447, 8 d'agost). Convé de recordar que el 3 d'octubre de 1436 el procurador reial de $\mathrm{Ma}$ lorca va establir a Guillem Sagrera i Jaume Servera in solidum un solar a la parròquia de Santa Creu. Vegeu Gabriel LlomparT, «Maestros albañiles y escultores en el Medievo mallorquín", BSAL, 49 (1993), p. 249-272.

23. ARM, Protocols, P-451; 1495, 1 de desembre.

24. ACM, Actes capitulars, 1622 (1431-36); 1432, 8 d'agost.

25. Ramon Rosselló Vaquer, Cronicó felanitxer $V$. Apèndix 2 (s. XIII-XVI), Felanitx, 1989.

26. ARM, Protocols, T-1102, 1440-1445. El notari que reuní aquests protocols, Joan Terriola, exercia de sobrestant de les obres reials a Mallorca.

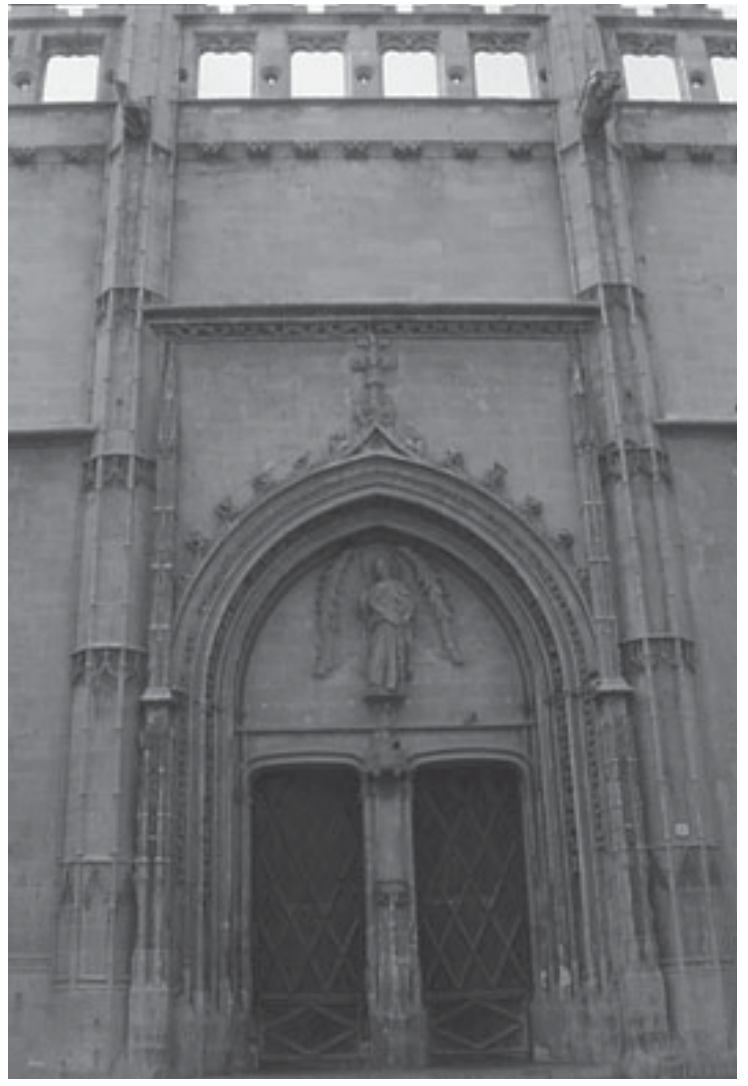

el mateix document a la construcció de sis finestres «ab dues corones», una pista important per fixar l'etimologia de les famoses «coronelles». De fet, el terme apareix en altres documents quatrecentistes; posem per cas, l'inventari aixecat l'any I495 de les cases del noble Salvador Sureda a l'Almudaina ens descriu una cambra que treu finestra "de duas coronas» a l'entrada ${ }^{23}$. En altres ocasions, la referència és més ambigua, com quan, el mes de març de I45 I, Guillem Vilasclar contracta l'acabament de sis finestres de la Llotja, quatre de les quals havien estat començades per Sagrera; aquí se'ns parla de «claravoyes y maynels sive corones».

A l'elenc d'obres sagrerianes, només puc afegirn'hi una i d'abast menor, encarregada pel capítol de la seu ${ }^{24}$ :

Foren vistes les reparations necessàries en lo Alberch del honor. Ardiacha per los discrets en $\mathrm{Jac}[\mathrm{me}]$ Auget fuster e Guillem Sagrera picapedres, en presència dels honor. Mossèn $P$. Seguí e Martí Axaló, canonges, a V d'agost any MCCCCXXXII.

Primo, en lo portal maior ha ops reparació estimada per ells a sis ll[iures].

Item són necessaris dos peus a la part del carreró estimats quatre ll., deu s[ous].

Item a la part dels predicadors reparacions necessàries estimades dues ll., deu s.

Item al ort un peu mitger entre lo dit alberch e la scola estimat a la part del dit alberch i ll. X s.

Item dues portes de la cuyna e una a la stable estimades IIII 11.

Item la teulada del corral, una biga e cent teules I ll. X s.

Item una porta a la payssa prop la font I $11 . \mathrm{X}$ s. Item és necessari fer portes a la cuyna demunt e reparar lo passatge e andador a les letrines IIII 11. Item recórrer lo trespol del menjador nou estimat I 11 .

Item recórrer les teulades I 11.

No es coneix amb exactitud la ubicació de la desapareguda casa de l'Ardiaconat. S'ha volgut identificar amb l'actual Can Cirera, però tots els indicis documentals apunten que ocupava un gran solar de la illeta veïna, que l'any i68 5 encara s'anomenava de l'Ardiaconat, cantonada amb el carrer de l'Estudi General. La visura era un tipus de feina habitual del mestre: el 26 de novembre de $\mathrm{I}_{442} 2$ estimava les obres necessàries a l'alberg del canonge Roderic Àlvar i l'i I de gener següent les de la casa de mossèn Pere Salvador ${ }^{25}$. Quant a Jaume Auget, fuster major de la seu, hem de suposar que era parent de Gabriel Auget, mestre de fusteria de les obres reials a Mallorca ${ }^{26}$.

Un dels temes que fretura de ser aclarit és el genealògic ${ }^{27}$. De moment, una relectura pacient dels documents coneguts permet fer precisions sigper desenredar aquest tema es deuen a Gabriel Alomar, «Los discípulos de Guillermo Sagrera en Mallorca, Nápoles y Sicília (I), Napoli nobilísima, III/III (1963), p. 85-96; «Los discí-
27. Els primers intents seriosos pulos de Guillermo Sagrera en Mallorca, Nápoles y Sicília (II)», Napoli nobilísima, III/IV (1963), p. 125-135. La informació fou reutilitzada en la seva monografia de l'any 1970, en particular en el capítol vir. 
nificatives a l'arbre familiar. En síntesi, Guillem era fill del felanitxer Antoni Sagrera que proporcionà pedra per a la fàbrica de la catedral entre I 390 i I 4 I 7. D'un germà d'aquest Antoni - potser Guillem Sagrera, un barquer que, l'any I 390 , traginava la mateixa càrrega pètria - va néixer Miquel Sagrera, picapedrer - de qui se sap que, el I397, també tallava pedra per a la seu-, i d'aquest devia ser fill un altre Miquel, així mateix picapedrer. Aquest segon Miquel declarà a favor del nostre arquitecte en el plet de la Llotja, del qual es proclamà assalariat durant dotze anys $\mathrm{i}$ "parent llunyedà» - de fet, si la meva hipòtesi és correcta, era fill d'un cosí-. $\mathrm{Ha}$ de ser el mateix que treballava a la catedral devers els anys I44I-I445, el que contractà a mitjan I446, juntament amb Guillem Vilasclar, l'acabament de la Llotja, i el mes de febrer següent, ara en solitari, la prossecució de l'església de Nostra Senyora de Gràcia - en aquest cas, intitula «oncle» el seu mestre $^{28}$. També l'haurem d'identificar - sempre amb tota la cautela que exigeix la inalterable onomàstica familiar - amb el contractista d'una reforma de l'adoberia del blanquer Jaume Domingo, l'any I474, per valor de vint lliures ${ }^{29}$.

Dels germans de mestre Guillem, només es coneixia l'existència d'un Antoni, encara enigmàtic. Potser és l'homònim que exercia de jurat a Felanitx l'any I4 Io i el que, juntament amb Joan Sagrera i altres vilatans, inclosos dos membres de la família Vilasclar, s'ofereix voluntari per defensar el castell de Santueri l'any I424, durant la guerra contra els genovesos ${ }^{30}$. En canvi, un seu fill homònim va ser un dels membres més actius de la dinastia sagreriana; sempre és qualificat de lapiscida. Sovint, se’l confon amb el fill primogènit de Guillem, també anomenat Antoni, que mai no fou picapedrer, sinó mercader, baldament es guanyés la vida comerciant amb pedra. No caldrà desenvolupar aquest argument: el pas de picapedrer a mercader $-\mathrm{i}$, en el nostre cas, el negociant firava amb material lapidi, que no era precisament barat- no és anecdòtic ni assenyala matisos diferents d'una mateixa realitat professional, sinó que, ben al contrari, pressuposa un salt d'escala estamental i palesa la delera de promoció social del primogènit del mestre. Ben mirat, no fa sinó compartir l'anhel de la immensa majoria de menestrals de l'època per transcendir el seu nivell social, definit per la pràctica d'un ofici manual, és a dir, innoble. No obstant l'ambigüitat del seu rang, un mercader podia ascendir fàcilment en la jerarquia social si era capaç d'acumular riquesa. És prou significatiu que, dels vuit fills coneguts d'en Sagrera, només un es dediqués amb tota seguretat a la professió paterna. Tant en general -és a dir, en tota societat que organitza el treball per mitjà d'una estructura gremial endogàmica - com en aquest cas concret, la perpetuació de la professió paterna estava més que justificada: era necessari amortitzar el taller familiar, retenir els millors càrrecs públics

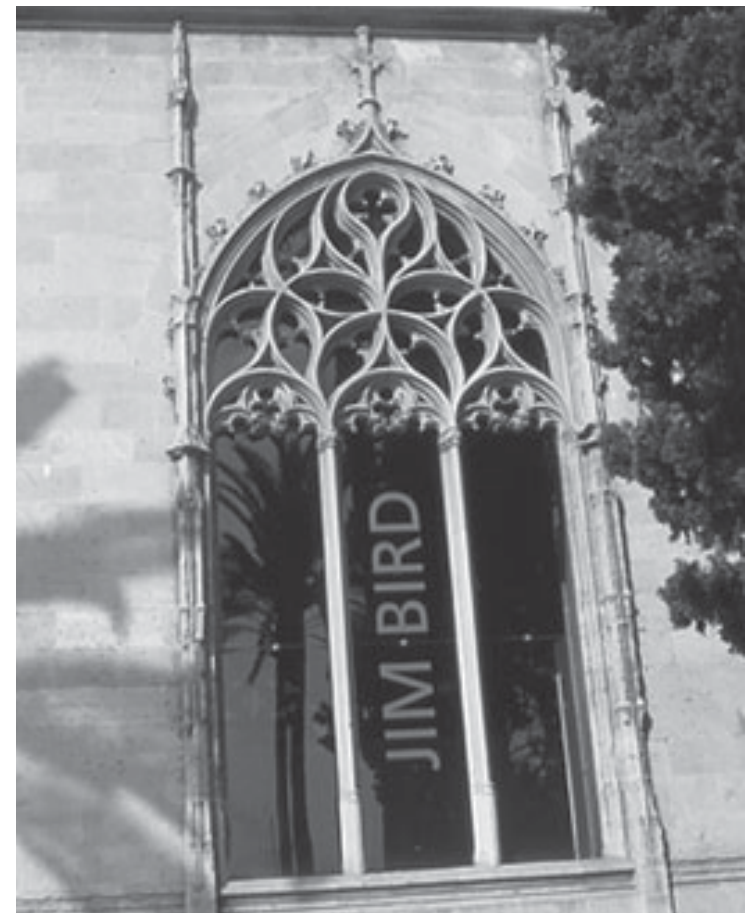

Figura 3.

Guillem Sagrera i Guillem Vilasclar: Llotja de Palma, finestra del costat de migjorn. Foto de l'autor.

(aquest fill va ser mestre major de l'Almudaina) $\mathrm{i}$ garantir la solvència econòmica d'almanco un dels descendents. Les dues filles del mestre no foren del tot mal casades, amb un sastre i un cirurgià benestants, mentre que la resta de fills foren un notari i dos eclesiàstics -l'un, frare, i l'altre, prevere.

Així doncs, Antoni Sagrera, nebot d'en Guillem, és el picapedrer que en diverses ocasions treballa pedra per a les obres reials napolitanes (I 448, I45 I, I452, I 453 , I 454, I 455 ), el mateix que l'any I 436 cobra algunes reparacions fetes a les muralles de Ciutat i qui l'any I440 s'encarrega de tallar pedra negra per al paviment de la Llotja ${ }^{31}$. Sovint treballava associat amb els Vilasclar. De moment, la seva primera obra documentada és el porxo que, l'any I 435 , va afegir a la capella del mercader Nicolau Gener a l'església de Sant Francesc de Palma ${ }^{32}$, mentre que

28. Miquel Sagrera «menor» estava casat amb una Pereta. Diverses vegades reconeix deutes per roba: el 26 de març de 1466 (ARM, Protocols, 2585, f. 78); el 15 de desembre de 1468 , juntament amb la muller i un fill homònim (ARM, Protocols, 2614); el 15 de febrer de 1469 , juntament amb el picapedrer Pere Cervera (ARM, Protocols, 2614); l'11 de març de 1469, juntament amb Antoni Sagrera, col-legial de Lluc (potser un germà), i altres persones (ARM, Protocols, 2614). El 12 d'octubre de 1470, era elegit àrbitre en un litigi entre dos notaris per l'intercanvi de les cases respectives (ARM, Protocols, 2611) i el 26 de març de 1471 nomenava procurador el notari Gaspar Alsamora (ARM, Protocols, P-278, f. 217). És el mateix que el 26 de setembre de $1475 \mathrm{col} \cdot$ locava de serventa la néta Pereta, de nou anys i filla d'un tercer Miquel Sagrera, ja difunt, a casa del pescador Francesc Oríes (Ramon Rosselló Vaquer, Cronicó felanitxer. Apèndix, s. XIII-XVI, 1986 p. 44. Aquest document és transcrit íntegrament per Maria Barceló i Gabriel Llompart, «Quaranta dades d'art medieval mallorquí», BSAL, 54 (1998), p. 85-104, doc. 23). També era pare d'un Guillem Sagrera, picapedrer documentat l'any 1471, i d'Antonina, que, l'any 1496, va contreure matrimoni amb el mariner Miquel Grec. No és segur que puguem identificar aquest darrer Guillem Sagrera amb el picapedrer agermanat Gabriel (error per Guillem?) Sagrera, «gran traidor, gran lladre e molt mal home, sermonador e avalotador, gran perseguidor dels mascarats [...] molt furiós», que s'encarregava d'enderrocar cases per manament del felanitxer Joanot Colom, en companyia del qual volgué fugir de l'illa. També era aferrissat partidari de la Germania el picapedrer Miquel Sagrera «jove», "afectíssim e sermonador, gran lladre e molt afectat a Colom», de qui es declarava nebot. Vegeu J. M. QuAdRado: Informacions judicials sobre'ls adictes a la Germania en la Ciutat e illa de Mallorca e penes de cos e d'haver a ells imposades après la reducció de 1523, Palma, 1896, p. 9, núm. 63 i p. 89, núm. 1142; Margalida BERNAT, «Libre de Reparations de Cases de la present Ciutat de Mallorques (1525)», BSAL, 56 (2000), p. 117-144.

29. Maria Barceló, «Nous documents...», 2003, p. 227, doc. VII.

30. Pere Xamena i Ramon Rosselló Vaquer, Història de Felanitx, vol. I, Palma, 1976, p. 174 i 188.

31. Són significatius a bastament els pagaments fets pel lloctinent reial per pedra destinada a la cort napolitana, "an Anthoni Sagrera, picapedres, fill d'en Anthoni Sagrera, e Anthoni Sagrera, mercader, fill e procurador d'en Guillem Sagrera, picapedres de Mallorca resident en la Ciutat de Nàpols [...]». Vegeu Joan Muntaner Bujosa, «Piedra de Mallorca en el Castelnovo de Nàpoles. Datos para la biografía de Guillermo Sagrera», BSAL, 31 (1960), p. 615-630, doc. II.

32. ARM, Protocols, M-159; 1435, 12 de juliol. El porxo fou construït amb la col-laboració del fuster Simó Geubert. El document recull la promesa d'acabarlo a finals de mes i incorpora una àpoca de vint-i-quatre lliures. La capella deu ser la que allotjava la tomba del client, al claustre: «Família de Janers, Armes: un abre ab dos Leons en camp de or. Consta del testament de Jaumeta, muller del Honrat Guillem Janer, en poder de Nicolau Prom, notari, a 3 Abril 1376. Elegesch sepultura en el Monastir de Sant Francesch en el Claustro, baix las columnas en el carner de mon marit, junt en el carner de Sabaters». Vegeu Ramon Calafat, Llibre de Antiguatats de la Iglesia del Real Convent de Sant Francesch de la Ciutat de Mallorca (1785), Palma, 1928, p. 99. 
33. Gabriel Llompart, «Sagreriana...», p. 421, doc. 5 .

34. ARM, Protocols, 2473; 1433 , 18 d'agost (només se'n conserva l'encapçalament). L'única descendent coneguda de la parella és una Joaneta, que es casà amb el barber Joan Belloch. La testadora encara vivia l'any 1461, perquè el 9 de maig d'aquell any, juntament amb el marit i la filla, ven un censal (ARM, Protocols, P-341).

35. A. Cañellas (transcripció), "Talla para una armada contra los corsarios. Año 1449», BSAL, 24 (1932-33), p. 11 (citat per Gabriel Alomar, p. 75. Cfr. supra nota 2).

36. Gabriel Llompart, «Sagreriana...", p. 431, doc. 11

37. ARM, Protocols, P-275; 1443, 19 de febrer. En el mateix protocol, el 9 d'abril de 1443, Guillem Sagrera nomena procurador el notari Montserrat.

38. ARM, Protocols, M-229; 1444, 27 de gener. El censal, però, era propietat mancomunada amb vuit persones més.

39. ARM, Protocols, M-230; 1445,4 de novembre.

40. ARM, Protocols, M-249; 1446, 16 de juliol.

41. Gabriel Llompart, «Miscelánea de arquitectura...», p. 100, doc. Ix. El 6 de febrer de 1447 Guillem signava àpoca de 150 lliures per la fàbrica de l'esmentada església, incloses «ille septuaginta libras pro nomine meo solute Anthonio Sagrera, nepoti meo [...]) De continent, el nebot (però, nebot llunyà) Miquel Sagrera es comprometia a acabar les obres.

\section{ARM, ECR, 493, f. 69 v.}

43. ACA, Cancelleria, Reg. 2732, f. 34; 1450, 14 de febrer El seu procurador era el notari Guillem Montserrat, que vengué dues cases del carrer d'en Cabara per 17 lliures, mentre que el picapedrer n'esperava obtenir 60 lliures, raó per la qual sol-licitava l'anul-lació de la venda. El mateix dia demanava al monarca poder lluir un censal que prestava al difunt Antoni Salvador.

44. ACA, Cancelleria, Reg. 2732, f. 127; 1450, 23 de desembre. Llavors, Antoni era un dels mestres de la fàbrica de Castelnuovo.

45. Ramon Rosselló Vaquer, Mestre Guillem Sagrera, p. 3. El censal es prestava per unes cases situades dins la vila de Felanitx, que havien estat propietat del pare d'Antoni Sagrera, és a dir, d'un germà del nostre arquitecte.

46. ARM, Protocols, 6249; 1458, 16 d'agost.

47. Maria Barceló, Semblança de Guillem Vilasclar, p. 42.

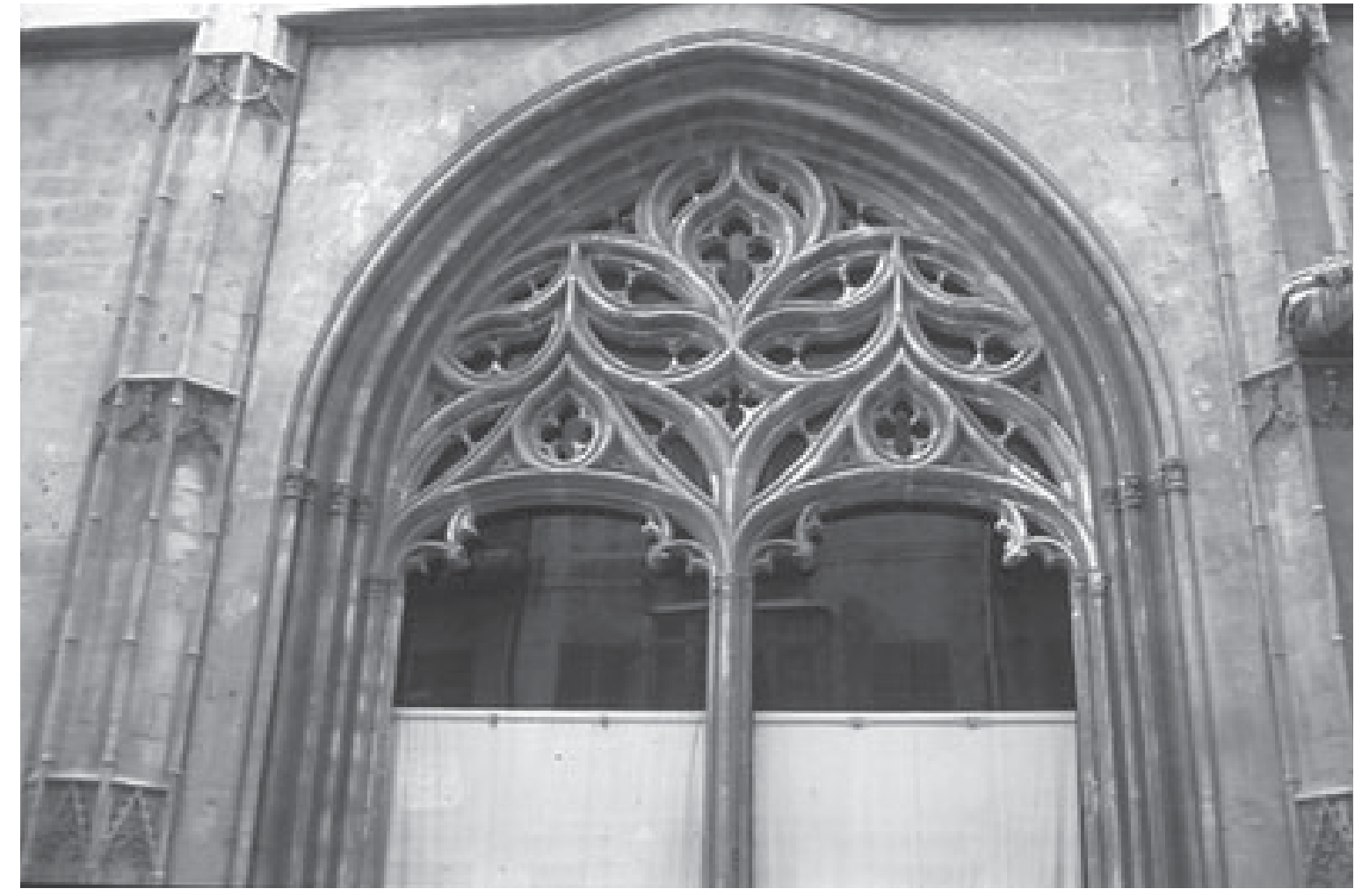

Figura 4.

Taller de Guillem Sagrera (Guillem Vilasclar?): Llotja de Palma, portal esquerre de la façana nord (detall). Foto de l'autor.

la saguera és la reforma efectuada entre I 474 i I 480 a les cases del cavaller Pere Joan Albertî3. Sempre que l'homonímia no ens jugui una mala passada, aquest Antoni estava casat amb una Salvadora, que, l'any I433, embarassada, dictava testament ${ }^{34}$. L'any I 449 residia en una casa pròpia, a l'illa d'en Guillem Blanch de la parròquia de Santa Eulàlia ${ }^{35}$. Uns altres documents ens informen del contracte d'aprenentatge subscrit amb el sicilià Jorbando Lopilato (I440) ${ }^{36}$, del nomenament com a procurador del notari Guillem Montserrat ( 1443$)^{37}$, de la venda d'un censal de cent lliures de preu (I444)

48. ACA, Cancelleria, Reg. 2735 , f. $124 \mathrm{v}$.

49. Maria Barceló, Semblança de Guillem Vilasclar, p. 39

50. Ramon Rosselló VAQUeR, Cronicó felanitxer VI Apèndix 3 (s. XIV-XVI), Felanitx, 1993.

51. Ramon Rosselló Vaquer, Cronicó..., 1986, p. 69.

52. Riccardo FilangIERI, Rassegna critica delle fonti per la storia di Castelnuovo, 4 vols., Nàpols, 1936-1940, vol. II.

53. Ramon Rosselló VAQueR, La pedra "de Santanyí.. Publica aquest autor que, a finals del
1450, el rei vol que es paguin a Antoni Sagrera, un dels mestres de Castelnuovo, les obres fetes a l'església de Nostra Senyora dels Àngels, extramurs de Ciutat de Mallorca.

54. ACA, Cancelleria, Reg. 2732, f. 33 v.; 1450,14 de febrer. A l'època, està documentat un Antoni Salt, mercader i lloctinent del procurador reial.

55. Ramon Rosselló Vaquer, Cronicó, 1986, p. 23.

56. ARM, Protocols, 6249; 1460, 2 de juliol.

57. L'any 1450 , el rei concedia la batllia de Felanitx a un Joan Sa- de la confessió de tenir en comanda divuit lliures i escaig del mercader Pau Moià (I445) ${ }^{39}$, del nomenament com a procurador de l'escriptor Llàtzer Sacorbella (I 446$)^{40}$, de la consignació de setanta lliures feta a favor seu per l'oncle Guillem Sagrera sobre el salari per la construcció de l'església de Nostra Senyora de Gràcia de Palma (I447) ${ }^{41}$, de la venda d'un tros de terra al camí de S'Aranjassa $(\mathrm{I} 448)^{42}$, de la demanda de restitució de dues cases que havia malvenut un seu procurador (1450) ${ }^{43}$, d'una concessió d'aigua de la sèquia de la ciutat - mitjançant un forat del diàmetre d'una moneda grera. Vegeu Ramon Rosselló VAQUeR, Mestre Guillem Sagrera, p. 6 . No sé per quina raó, Gabriel Alomar convertia Joan i Miquel Sagrera en germans i, alhora, cosins de Guillem, ni es coneix el document original en que es basava R. Filangieri per identificar Joan com a cosí del nostre Guillem.

58. ACA, Cancelleria, Reg. 2918 f. 49; 1451, 3 de novembre. En realitat, la corretja havia estat cedida pel picapedrer a l'esposa quan es traslladà a Nàpols per servir el rei.

59. ARM, Protocols, G-99: un Joan Sagrera i la muller Bartomeua venien un tros de terra a Felanitx el 4 de maig de 1461. El 6 de maig de 1468, dicta testament un Berenguer Sagrera de Felanitx, casat amb Mateua i pare de Cristòfol, Miquel, Joan, Bartomeu iSimó (aquest, ja finat, era pare de Miquel i Bernat). El 13 de juliol de 1487 , redacta testament un gendre de l'anterior, Esteve Bordoi, i li fa de marmessor el cunyat Joan Sagrera, picapedrer de Felanitx. D'altra banda, el 22 de novembre de 1473, un Joan Sagrera, picapedrer, signa un rebut als oncles Joan Ferrer i fra Antoni Ferrer, mercedari, per tots els béns que li han cedit per la legítima de Joaneta, mare dels donants i àvia del dit Sagrera (ARM, Protocols, P-322). Anys més tard, el 18 d'agost de 1498, Joan Sagrera, mestre major de la seu, i Francesc Sagrera, prevere, confessen deure a un merca- 
d'un diner - per a ús domèstic de la seva casa del carrer d'en Mas «anomenada la Sinagoga» (I 450$)^{44}$, de la donació feta a la neboda Antonina Julià de Felanitx d'una porció censal $(1456)^{45}$, de la venda per cinquanta lliures d'un «hospicio» a Felanitx pertanyent a la seva muller $(1458)^{46}$, de la comissió d'una valoració de pedres feta en companyia de Guillem Vilasclar (I 458$)^{47}$, d'una segona concessió d'aigua de la sèquia de Ciutat mitjançant un orifici del diàmetre d'una moneda de dos diners $(\mathrm{I} 457)^{48}$, de la seva actuació com a testimoni en les noces del picapedrer Bartomeu Cifre amb Eulàlia Vilasclar $(\text { I } 459)^{49}$, de la consignació de vuit sous per construir un forn en unes cases de l'antiga sinagoga de Santa Eulàlia ${ }^{50}$ i d'un deute de catorze lliures per un drap cordellat (I460) ${ }^{51}$. Viatjà a Nàpols en diverses ocasions per acompanyar la pedra que s'hi enviava; a més, va intervenir en les obres de Castelnuovo i, probablement, en la reforma de la fortalesa de Gaeta (1455) 52 .

Gràcies a Ramon Rosselló, podíem saber que va treballar en el monestir de Jesús ${ }^{53}$, però una reexaminació del document original ens permet de precisar l'abast de la seva intervenció. En efecte, una lletra reial consignada al governador de Mallorca recorda que Antoni Sagrera i Huguet Barxa havien treballat en la construcció de l'església dels franciscans observants («fabricarunt et laborarunt per aliquot tempus in eclesia Beate Marie Angelorum extramuros»), llogats per Antoni Salt - pel que sembla, es tracta d'un administrador o sobrestant, no necessàriament d'un mestre d'obres -, fins que, a la mort d'aquest últim, assumiren personalment l'acabament de la fàbrica. Ara reclamaven als hereus del difunt el que se'ls devia ${ }^{54}$. Com és prou sabut, el monestir de Jesús fou fundat l'any I 44 I pel pare Bartomeu Catany, gran predicador i difusor de la doctrina lul-liana. Hi havia notícia que les obres de l'església, dedicada a la Mare de Déu dels Àngels, començaren l'any $\mathrm{I} 444$, $\mathrm{i}$ ara hi podem afegir que s'havien completat sis anys més tard. L'expeditesa constructiva és comprensible, perquè era un edifici més aviat modest, com deixen entreveure els pocs records fotogràfics anteriors a la seva desaparició definitiva a finals del segle xIx. Qui sap si aquest picapedrer és «lo senyer en Toni Sagrera picaperes» que ingressava malalt a l'Hospital General el 4 de gener de $1488^{55}$. Si fos així, el mestre hauria arribat a una edat provecta, atès que superà la setantena. És més cert que tenia tres germanes, d'acord amb el testament que una d'elles, Caterina, va redactar l'any $1460^{56}$. Estava casada amb Jaume Julià «major», de Felanitx, de qui tenia descendència - un fill i dues filles - ; la germana Tomasa era la muller del traginer felanitxer Francesc Bordoi, i la germana Joaneta ho era de Cristòfol Julià, de la mateixa vila.
El testament de Caterina també esmenta l'oncle Joan Sagrera, resident a Felanitx, que haurem d'afegir a la llista de germans de mestre Guillem, llevat que vulguem donar un valor molt genèric a la paraula «oncle». No se'ns informa de la seva professió, però no és inversemblant que fos picapedrer, potser l'homònim o el pare de l'homònim que participà en les obres de Castelnuovo (I454) $\mathrm{i}$ que -si acceptem la hipòtesi de Gabriel Alomarcontractà la fabricació d'una finestra del palau

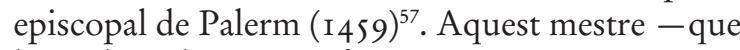
la tradició historiogràfica, sense arguments prou sòlids, ha convertit en cosí de mestre Guillem - ja treballava a Nàpols l’any I45 I, quan demana la intercessió del rei per tal de recuperar una corretja d'argent blanc que li havia deixat en testament la seva dona Francina, oriünda d'Inca i filla de Marc Veri ${ }^{58}$. En canvi, per raons cronològiques, el Joan Sagrera documentat entre 1473 i I 503 a Mallorca, mestre major de la seu i de l'Almudaina, n'ha ser un descendent ${ }^{59}$. Aquest segon Joan Sagrera, l'any I 480, era casat amb Antonina, filla del picapedrer felanitxer Joan Ballester ${ }^{60}$. Resta per identificar el Joan Sagrera que l'any I 437 treballava a Lleida com a collaborador de Rotllí Gautier -l'antic soci de mestre Guillem a Perpinyà, mort l'any I44 I a Lleida - i que cinc anys més tard ho feia a València, en la porta del cor de la catedral, a les ordres d'Antoni Dalmau ${ }^{61}$. A primera vista, sembla fàcil d'identificar amb el germà del nostre arquitecte, però també podria tractar-se d'un seu fill fins ara desconegut, de moment anònim i sense professió coneguda. D’aquest, només en puc dir que va morir a Sicília l'any I443: «Item divendres a xx del dit mes [desembre de I443] celebraren les misses per ànima del fill de mestre G[uille]m Sagrere picapedres qui morí en Secília, rabí per pa que portaren net de quart, 8 sous [...] Item rabí per loguer de quatre antorxes que li loguí al dit Gm. Sagrera, I lliura» ${ }^{62}$. Tampoc no he reeixit a aclarir la filiació d'altres Sagrera documentats al darrer quart del segle xv, potser nebots o, millor encara, nebots llunyans de l'arquitecte.

Hom diu que Guillem es casà dos cops, amb la perpinyanesa Jaumina Tura, que va morir l'any I432 i va ser presumptivament enterrada a la catedral - com semblava lògic de conjecturar gràcies a la làpida sepulcral dels Sagrera-, i amb la sollerica Caterina Frontera, que va finar devers l'any I 469. Però, en realitat, la primera fou inhumada a la parròquia de Santa Eulàlia ${ }^{63}$. En canvi, el 8 de febrer de 1438 sí que era sepultada a la seu una segona muller del mestre, anònima i fins ara desconeguda ${ }^{64}$. Sigui com vulgui, l'arquitecte sols va tenir descendència de les dues consorts de moment identificades. Fills de la primera foren Antoni, mercader - el responsable d'adquirir pedra de Santanyí per a la cort napolitana, però mai professional de la construcció, com der 13 lliures i escaig per llana aragonesa (ARM, Protocols, S-576, f. 20). El 29 de juliol de 1500, Jaume Bordoi, habitant a Nàpols, ven a Joan Sagrera «major», picapedrer de Felanitx, una peça de terra al lloc dit «Lo Clergue», al terme de Felanitx, per 38 lliures (ARM, Protocols, G-96). Poc després, el picapedrer Miquel Amorós collloca per cinc anys el seu esclau Domingo Fàbregues amb el collega Joan Sagrera (ARM, Protocols, M-590, f. 5 v.). Aquesta notícia m'ha estat amablement comunicada per Maria Barceló.

60. J. Rosselló Lliteras, Els pergamins de l'Arxin parroquial de Santa Eulàlia, vol. III (14001545), Palma, 2000, p. 110, doc. 1089; 1480, 28 de juny (Felanitx): testament de Miquela, vídua de Joan Ballester, picapedrer de Felanitx. Llega deu lliures a la filla Antonina, casada amb Joan Sagrera, el qual també actua com a marmessor. Aquest era pare d'un tercer Joan Sagrera, picapedrer, casat amb Caterina Soler.

61. M. Caterina Argilés, «Preus i salaris a la Lleida dels segles XIV i xv segons els llibres d'obra de la seu», tesi doctoral, Lleida, 1992 (es pot consultar per internet); $\mathrm{M}$. Rosa TERés, "Art i arquitectura a la Seu Vella de Lleida en temps d'Alfons el Magnànim», Seu Vella. Anuari d'Història $i$ Cultura, 3 (2001), p. 55-122; Mercedes Gómez FERrer, «La cantería valenciana en la primera mitad del siglo xv: el maestro Antoni Dalmau y sus vinculaciones con el área mediterránea», Anuario del Departamento de Historia y Teoría del Arte (UAM), IX-X (1997-1998), p. 91-105.

62. Acm, Llibre de sagristia, 1137 , any 1443 , f. 25 v.

63. ACM, Llibre de sagristia, 1127 , any 1432 , f. 8 v.: «Item reebí dijous a XXIIII del mes [abril] per la quarta del pa de la muler d'en Sagrera que fo soterrada a Sta. Eulàlia XV pans, valen dos sous e sis diners». No se'ns dóna el nom del mestre, però se sobreentén. Un lapsus calami justifica que el document fos datat l'any 1430; la seqüència dels llibres de sagristia permet establir l'any correcte. En el volum següent (1128), que correspon a l'any 1433, apareixen consignades les morts d'un jove, «qui morí en casa en Sagrera mestre de la obra» (28 d'agost) i d'un esclau de l'arquitecte (13 de setembre).

64. ACM, Sagristia, anys 1437 1438, f. 26: «Item dissabte a vuyt del dit mes [febrer de 1438] fo soterrada la muler de mestre Gm. Sagrera picapedres, rebí per le offerte del pa net de quart, $8 \mathrm{~s} . » \mathrm{I}$ al f. 27: «Item rabí sinch s. de mestre $\mathrm{Gm}$. Sagrera picapedres, los quals sa muler lexà en son testament $a$ la sacrestia per dret parroquial». Aquesta segona muller devia tenir una salut delicada, perquè fou combregada a mitjan $1437 \mathrm{i}$ a inicis de l'any següent (ibídem, f. 60 v. i 63 v.). Llavors, l'arquitecte residia a la parròquia de l'Almudaina. 
65. ACA, Cancelleria, Reg. 2657, f. 233 v.; 1449,6 de juny: carta d'Alfons el Magnànim al loctinent de procurador reial de Mallorca, Joan Albertí, des de Castelnuovo: «Lochtinent, aquî va lo fill de mestre Guillem Sagrera per fer tallar e portar certes pedres les quals són necessàries per la obra de aquest nostre castell; menam-vos expressament que en tot lo que aquell haurà mester per fer les dites pedres doneu tota la ajuda e favor que us serà possible e no permetau qu fusta nenguna parta de aquí per venir ací que no porte per gorr la més quantitat que porà de les dites pedres e per res no fesseu lo contrari ne ho dileteu car no ho pendrem $a b$ paciència». En canvi, atès que el document l'intitula "mestre», ha de tractar-se del seu cosí el personatge esmentat en una altra carta, dos anys posterior (ACA, Reg. 2720; 1451, 2 de gener): «Nos trametem aquí lo feel nostre Antoni Segrera a qual havem dat càrrech nos porta certa quantitat de pedra, la qual havem mester per les obres que em fer. Manam-vos per ço que dit mestre Antoni donets tot lo que necessari haia per comprar la dita pedra e fer carregar aquella donant-li tota endreça e ajuda que mester haurà per açò. E en açò no metats dilatió alguna com no puxam les dites obres continuar sens la dita pedra».

66. ACA, Cancelleria, Reg 2734; 1456, 21 de novembre: «Amats e feels nostres. Havent entès que mestre Guillem Segrera ${ }^{\circ}$ mentres vivia tenia la Maestria de la fàbrica de la Seu de aquexa nostra ciutat de Mallorques, de qual essent restat entre los altres un fill appellat Jacme Segrera a qui sens dubte li's pot acomanar qualsevol subtil fàbrica com se sforça en seguir los vestigis del dit son pare e en la fàbrica del nostre Castell nou ne havem vista la experiència, per tant vos pregam encarregam stretament que tant per meritar-ho lo dit Jacme quan encara per los serveys que de dit son pare havem rebut e d'el rebem cascun dia li vullau fe comanar la Mestria de la fàbrica de la dita Seu, segons tenia lo dit on pare. Avistant-vos que per os respectes damunt dits vos ho haurem a singular complacèntia $e$ accepte servey».

67. L'any 1449 , el rei li concedeix el primer benefici eclesiàstic vacant de nominació reial (ACA, Cancelleria, Reg. 2730, f. $184 ; 1449,15$ de juny). Dos anys més tard, reitera enèrgicamen a gràcia, invocant una butlla de Nicolau V (ACA, Cancelleria, Reg. 2918, f. 49 v.; 1451, 15 de desembre).

68. L'any 1468, Francesc Sagrera era també un dels obrers de la confraria de Sant Jordi, amb seu a l'església que ell mateix regia, que contractà el cèlebre retaule de Pere Niçart i Rafael Mòger. Un document que fa referència al dot nupcial d'una seva reneboda (les mil lliures que aportà

ja he dit $-{ }^{65}$; el fill anònim (potser Joan?), que va morir a Sicília l'any I 443; Jaume, picapedrer documentat entre I 449 i I 48 I, mestre major de l'Almudaina (I449-I48I), un dels continuadors de l'obra del seu pare a Castelnuovo (I454), aspirant a mestre major de la seu mallorquina valentse d'una sol-licitud d'Alfons el Magnànim als jurats i al capítol ( 1456$)^{66}$, i un dels constructors de dues naus de les drassanes napolitanes ( 1465 ), i Francesc (ca. I432-I 509), prevere (beneficiat a la seu ${ }^{67}$, rector de Sant Antoni de Pàdua ${ }^{68}$, aspirant frustrat l'any i 450 a la rectoria de Felanitx ${ }^{69}$ i dos anys després a la de Manacor ${ }^{70}$ ) i tracista d'obres d'arquitectura i escultura, com ara el portal de l'Almoina de la catedral (I499), el monument funerari en alabastre de Ramon Llull (I487) i l'antic retaule major de la parròquia de Manacor (I499, pintat per Pere Terrencs). No coneixem la progènie d'Antoni i Jaume, si és que reeixiren a tenir-ne; ho fa dubtar que el plet contra la Mercaderia fos assumit pel fill eclesiàstic - encara que sempre havia representat els interessos dels seus germans, des del $\mathrm{I} 504$ actuà en solitari- i, després, per la família CaldenteiSagrera, gràcies a la cessió de tots els béns i drets de Francesc a favor del seu nebot Guillem Caldentei, doctor en medicina.

Anna Caldentei quan es casà l'any 1431 amb Macià Ferrer de Santjordi) ens permet de saber que Francesc Sagrera va testar el 17 de gener de 1509 davant el notari Miquel Litrà, els protocols del qual no s'han localitzat (ARM, Protocols, 1165; 1533, 19 de juliol).

69. Ramon Rosselló va documentar la sol-licitud d'Alfons el Magnànim al papa a fi d'obtenir la rectoria de Felanitx per a Francesc Sagrera, com recull una carta del mateix rei al governador de Mallorca, datada el 15 de setembre de 1450 (Ramon Rosselló Vaguer, Mestre Guillem Sagrera..., p. 6). La carta dirigida al governador de Mallorca es troba a ACA, Cancelleria, Reg. 2731, f. 80 v., però hi hem d'afegir les cartes dirigides al papa al cardenal de València (ACA, Cancelleria, Reg. 2732, f. 84 v. 92). S'hi oposà el cardenal de $\mathrm{Va}$ lència, és a dir, Alfons de Borja, que tenia un altre candidat. Atès que aquest era foraster, el $18 \mathrm{de}$ novembre del mateix any, el monarca es dirigia al cardenal recordant-li que la rectoria havia de ser per a un illenc $i$ insistia a afavorir el seu aspirant: «fill del feel e amat nostre en Guillem Segrera mestre maior de la obra del castell nou de la nostra ciutat de Nàpols, al qual tant per les virtuts honestat del dit Francesch quant per los acceptes e continus serveys que del dit mestre Guillem havem [...]». (ACA, Cancelleria,

Amb la muller definitiva, el nostre arquitecte va tenir almanco quatre fills més: Guillem, notari; Joan, frare dominic ${ }^{71}$; Agnès, casada l'any I456 amb el sastre Joan de Bretanya - vidu de Joaneta Escuder i, més tard, marit en terceres núpcies d'una Angelina - ${ }^{72}$, i Miquela, casada l'any I468 amb Antoni Caldentei, cirurgià de Felanitx ${ }^{73}$. Per raons desconegudes, l'arquitecte va excloure de l'herència els fills de la mallorquina, legítima a banda. Podem presumir que la muller disposava de suficients béns propis; de fet, un document la fa propietària d'una possessió o rafal, $\mathrm{Na}$ Moiana, a Sóller ${ }^{74}$. La degué heretar el fill Guillem, que cal identificar amb l'escrivent, oriünd de Ciutat de Mallorca, que l'any I47 I obtenia permís del monarca per exercir la notaria ${ }^{75}$. Poc li va durar l'alegria, ja que l'any següent moria i se n'aixecava l'inventari de béns ${ }^{76}$. A inicis del mateix I47I actuava com a procurador de la germana Miquela i el cunyat Antoni Caldentei, que havien venut un alberg a Pere Cavaller, sense respectar els drets que presumptivament hi tenia el canonge Antoni Bagur ${ }^{77}$.

D'acord amb el testament, conegut només per vies indirectes, que l'arquitecte va dictar a Pere Pugeriol, notari resident a Nàpols, els hereus foren els tres fills del primer matrimoni. Ja que Antoni i Jaume residien a la cort partenopea, a Mallorca

Reg. 2546, f. 61). En aquest cas, el rei va fracassar i va obtenir la rectoria l'aragonès Guillem Candela i, a la mort d'aquest, dos anys més tard, Sanxo Garcia, capellà del Magnànim (ACA, Cancelleria, Reg. 2918, f. 1 i 15 v.).

70. ACA, Cancelleria, Reg. 2918; 1452, 20 de juliol: cartes al papa i al cardenal Borja. El rei defensa els mèrits de Francesc Sagrera, que manté un plet a la cúria romana amb Jaume Ferrer sobre la rectoria de Manacor i Santa Maria de Bellver («Ecclesia de Monacor et de Pulcrovisu»). El 17 d'agost següent, el rei escriu als lloctinents generals de Mallorca - llavors Arnau de Vilademany i Francí d'Erillexigint que Sagrera mantingui la possessió de la rectoria.

71. Ramon Rosselló Vaquer, Mestre Guillem Sagrera, p. 5, n. 11. L'11 de març de 1469, fra Joan Sagrera, amb llicència del seu germà Guillem i del prior del convent, nomena procurador per cobrar del germà Francesc, prevere, els drets i llegats dels seus difunts pares.

72. Encara que no el transcriu, el pare Llompart (Sagreriana.., p. 415) esmenta un testament de Joan de Bretanya, datat el 1452. En efecte, es pot localitzar a ARM, Protocols, P-363, f. 17 v. El testador, que llavors nomenava hereva la seva ànima, manava fer un retaule de fusta dedicat a la Visitació per posar prop de la seva sepultura, a l'església dels dominics de Ciutat. Tres anys més tard, nomenava procurado a València per cobrar, del castellà Diego de Casser, «olim mecum morabatur», 28 sous que li prestà quan treballava a casa seva, «et qui hospite insalutato a domo mea recessit». Cinc dies més tard i davant el mateix notari, nomenava procurador, com a marmessor del castellà Fernando Ferro, el cunyat Jaume Sagrera, absent (ARM, Protocols, P-334, f. 46 i 46 v.; 1455, 21 de maig i 29 de maig). Abunden les referències documentals a Joan de Bretanya. Recordaré només el reconeixement d'un deute per cera, que signà amb el seu cunyat Francesc Sagrera (ARM, Protocols, 2614; 1467,14 de novembre) i la contractació d'un antic esclau seu amb Jordi Castell, quan hi era present el també cunyat Guillem Sagrera, escrivent (ARM, Protocols, M-445; 1468, 28 de juliol). Una filla del sastre, ja difunt, d'Agnès Sagrera, anomenada Joaneta, es casà l'any $1472 \mathrm{amb}$ el paraire Esteve Solà. El dot era de 150 lliures, que prometia pagar l'oncle Francesc Sagrera, prevere. Hi donà el consentiment l'oncle fra Joan Sagrera i hi actuà com a testimoni el parent Antoni Sagrera, picapedrer (ARM, Protocols, 2611, f. 191; 1472, 23 de novembre).

73. El dot de la núvia pujava a 150 lliures, com el de la germana

Agnès. Sembla que era propie tària del rafal Roig, a Porreres. La família Caldentei és molt coneguda i no caldrà entrar en detalls, però almanco recordem que Bartomeu Caldentei, mestre en arts i teologia, germà de l'esmentat Antoni, era un notable lul-lista $\mathrm{i}$ un dels introductors de la impremta a Mallorca; que Guillem Caldentei, nét del nostre arquitecte, fou un important metge, editor del comentari d'Ugo da Siena a l' Ars medica de Galè; que el seu fill Bartomeu Caldentei es casà l'any $1536 \mathrm{amb}$ una germana del famós jesuïta Jeroni Nadal, etc.

74. Ramon Rosselló Vaquer, Cronicó..., 1986, p. 44. Segons aquest autor, el 3 d'octubre de 1466, la vídua de mestre Guillem 


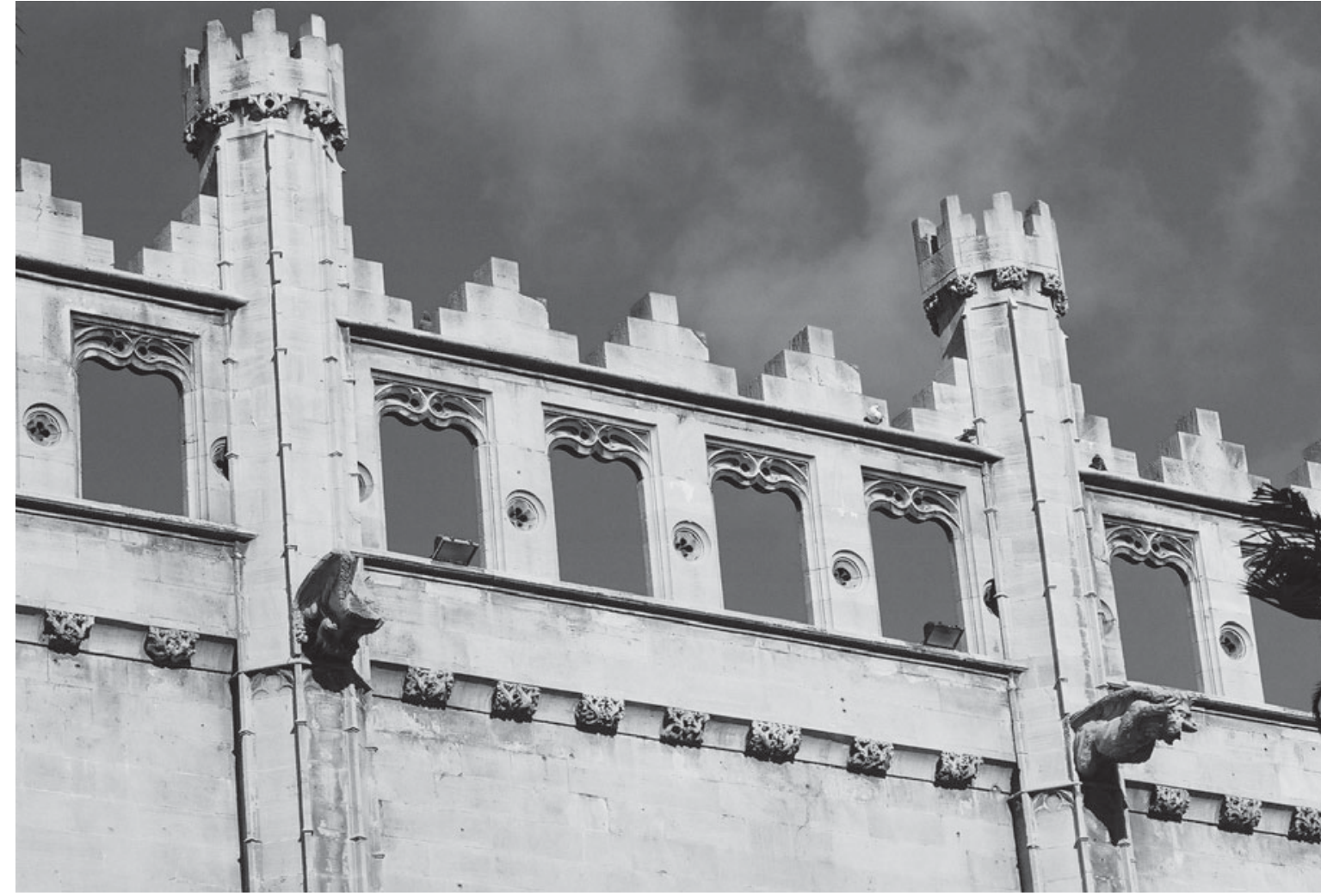

Figura 5.

Guillem Sagrera i altres: Llotja de Palma, coronament (detall). Foto de Donald G. Murray.

actuava en llur nom el germà Francesc. Això no vol dir que aquest no s'absentés de l'illa; a més de viatjar a Nàpols, sabem que era a Roma els anys $1466^{78} \mathrm{i}$ I $470^{79}$. Va ser l'encarregat de vendre els immobles heretats del seu pare. Però aquest és un tema enrevessat, que s'ha volgut resoldre massa aviat. Llis i ras, la ruïna dels Sagrera és una exageració, si no un mite, que es fonamenta en la declaració interessada dels hereus, en la venda d'alguns immobles i en el retorn a l'orde de predicadors d'un terreny per no haver d'assumir el censal que l'hipotecava. Però, com sempre, els documents i els fets es poden interpretar d'altres maneres. Per exemple: si bé és cert que l'any 1450 el rei escrivia al governador de Mallorca exigint que l'arquitecte no fos molestat, pertorbat ni inquietat pels creditors, que constantment acuitaven muller i fills ${ }^{80}$, també ho és que no hi ha indicis que ningú requerís el segrest per deutes dels seus béns. Que Sagrera al-legués «vellesa e povresa» per incoar el plet contra el Collegi de la Mercaderia és un recurs retòric, i que se'n fes ressò el monarca no és prou significatiu, atès que es tractava d'un seu protegit. L'argument pecuniari és magnificat l'any I456 pel fill Francesc quan evoca la frustració del difunt pare («granment fou descebut»), sobretot a causa de les pèrdues econòmiques («lesió e decepció») ocasionades per la construcció de la Llotja. Ell mateix -o el seu representant legal- addueix les argúcies més dramàtiques per reclamar doblers — «per causa de la dita obra ha haguda lexar la sua casa e la pàtria anant en terres estranyes [...] e axí los infants de aquell són restats sens alguna substància»-, com si a la terra d'origen s'hagués oblidat la vertadera motivació de la partença, encara que el ploricó també sabia discórrer raonaments més suggestius, com ara qualificar la Llotja de «bella e sumptuosa».

En tot cas, al meu entendre, el motiu de tanta desventura no era un error d'estimació del preu calculat per edificar la Llotja, vint-i-dues mil lliures, com pretenia Francesc Sagrera i ha repetit la historiografia fins ara, sinó la manca de perspicàcia o d'experiència comercial del seu pare. D'altra banda, la venda dels béns seents de la família era ineludible, ja que hi havia tres hereus, a més d'altres fills que tenien dret a la legítima i, sens dubte, la necessitat de liquidar els llegats sobreafegits $i$ les obres pies. A manca d'un inventari post mortem, la informació sobre aquest assumpte és escassa i fragmentària. Se sap que el 19 d'agost de I 420, de Perpinyà estant, Guillem Sagrera va vendre per vint lliures la casa que la primera muller aportà com a dot i el següent 9 de desembre, ja a Ciutat, comprava a terços, per vuit lliures, una casa (algorfa i botiga), prop de l'església de Sant Bartomeu, a la parròquia de Sant Nicolau, que va revendre deu anys més tard ${ }^{81}$. L'i i de febrer de I423, va adquirir, al notari Joan Mayrach, unes cases («hospicium»), amb algorfa incorporada,
75. Ramon Rosselló Vaquer, Cronicó..., 1986, p. 78. I, també, del mateix autor: La pedra «de Santanyì... El 16 de març de 1469 Guillem, escrivà, nomenava procurador l'oncle Bartomeu Frontera, de Sóller, per recuperar les pensions censals que li devien a aquella vila. De nou, l'11 de març de 1470, Guillem nomena procurador el sastre Miquel Grimalt per cobrar els crèdits que té a Sóller (ARM, Protocols, M-8, f. $108 \mathrm{v}$.).

76. Gabriel Llompart, «El llibre català a la casa mallorquina (1350-1550)», Analecta Sacra Tarraconensia, 48 (1975), p. 193-240, en particular p. 234 (l'original a ARM, Protocols, 2574; 1472, 24 de setembre). L'inventari fou instat pel sogre Joan Caselles, paraire, en nom de la filla Joana, prenyada, que residia a la casa paterna. Entre els escassos objectes, assenyalem la presència d'alguns llibres (formularis notarials, Boeci, Salms, Cobles d'Amor, etc.). S'hi consigna el crèdit de cent vint-i-cinc lliures contra mossèn Arbona i Francesc Arbona per una possessió que els va vendre. El llinatge dels compradors permet endevinar-ne l'origen solleric i em demano si no es tractarà de l'antiga propietat materna. Figura com a testimoni un Guillem Sagrera, prevere. A més, ARM, Protocols, 2571: 1473, 15 de febrer: Francesc Sagrera, prevere, i Antoni Caldentei, barber, prometen servar indemne el paraire Joan Caselles per la fiança de cinquanta lliures a favor de la cúria del batlle de Ciutat, a instància del curador de l'heretat del notari Guillem Sagrera.

77. ARM, Protocols, P-352, f. 40 v.; 1471, 6 de febrer: «Ja altra vegada en escrits sia stat intimat a vós discret en Guillem Segrera, escrivent, procurador de n'Anthoni Caldentell, cunyat vostre, e de la dona Miquela, germana vostre $[\ldots]$ ».

78. ACM, Actes capitulars, 1624, f. 4 v.; 1466, 7 de febrer.

79. ARM, Protocols, 2587: 1470, 12 d'octubre: el procurador del mercader Antoni de Verí convoca un Antoni Sagrera, prevere i beneficiat a la seu — segurament, l'homònim que era collegial de Lluc-, davant la porta del palau episcopal i li presenta una lletra de canvi contra Francesc Sagrera, llavors a Roma, de disset lliures i mitja, que havia fet efectives el mercader Checolo de Pichi.

80. Ramon Rosselló Vaquer, Cronicó..., 1986, p. 20.

81. Ramon Rosselló Vaquer, La pedra "de Santanyi».... Els altres compradors eren dos oficials de les obres de la seu, el fuster Gabriel Auget i el picapedrer Miquel Jordi. El venedor era el jurista Lluís Rossell. L'arquitecte va vendre la seva part per tres lliures al sastre Francesc Gasset, l'11 d'agost de 1430. 
82. Cosme BauzÀ, Historia de Felanitx, Felanitx, 1921, vol. III, p. 97. El document original de la primera compra es troba a ARM, Protocols, T-25. Era un establiment emfitèutic, carregat amb dotze lliures censals (preu total de cent cinquanta lliures); per això, l'arquitecte en lluïa un terç el 27 de gener de 1424. No he arribat a saber si va redimir la resta. Actuà com a testimoni de la compra l'imaginaire Llorenç Tosquella. La venda apareix registrada a ARM, Protocols, T-27. Hi apareix com a testimoni el sastre Joan de Bretanya, gendre de l'arquitecte.

83. ARM, Protocols, P-347, f. 25 v.; 1464, 4 de desembre.

84. Margalida Bernat, «Llocs perduts: Cementeris i sinagogues de Ciutat de Mallorca (segles XIII-Xv)», BSAL, 63 (2007), p. 7-40. El solar estava situat extramurs, al camí de Portopí, prop de l'actual Molinar de Ponent o Jonquet. Després es va convertir en plaça.

85. ARM, Protocols, 2533; 1456, 23 d'abril: Francesc Sagrera, fill i hereu de Guillem Sagrera, lapicida difunt, signa àpoca de vuit lliures a Guillem Frontera, de Sóller, per la conducta anual de «lo fossà dels Jueus".

86. Cfr. supra nota 22.

87. ARM, ECR, 494; 1457, 14 de maig.

88. Joan Muntaner Bujosa, Piedra de Mallorca...», p. 619; Ramon Rosselló VAQuer, La pedra «de Santanyi»... Llur font és l'arxiu del Reial Patrimoni (ARM), però la concessió reial es pot localitzar també a l'ACA (Cancelleria, Reg. 2918, f. 182 v.; 1452, 19 de desembre).

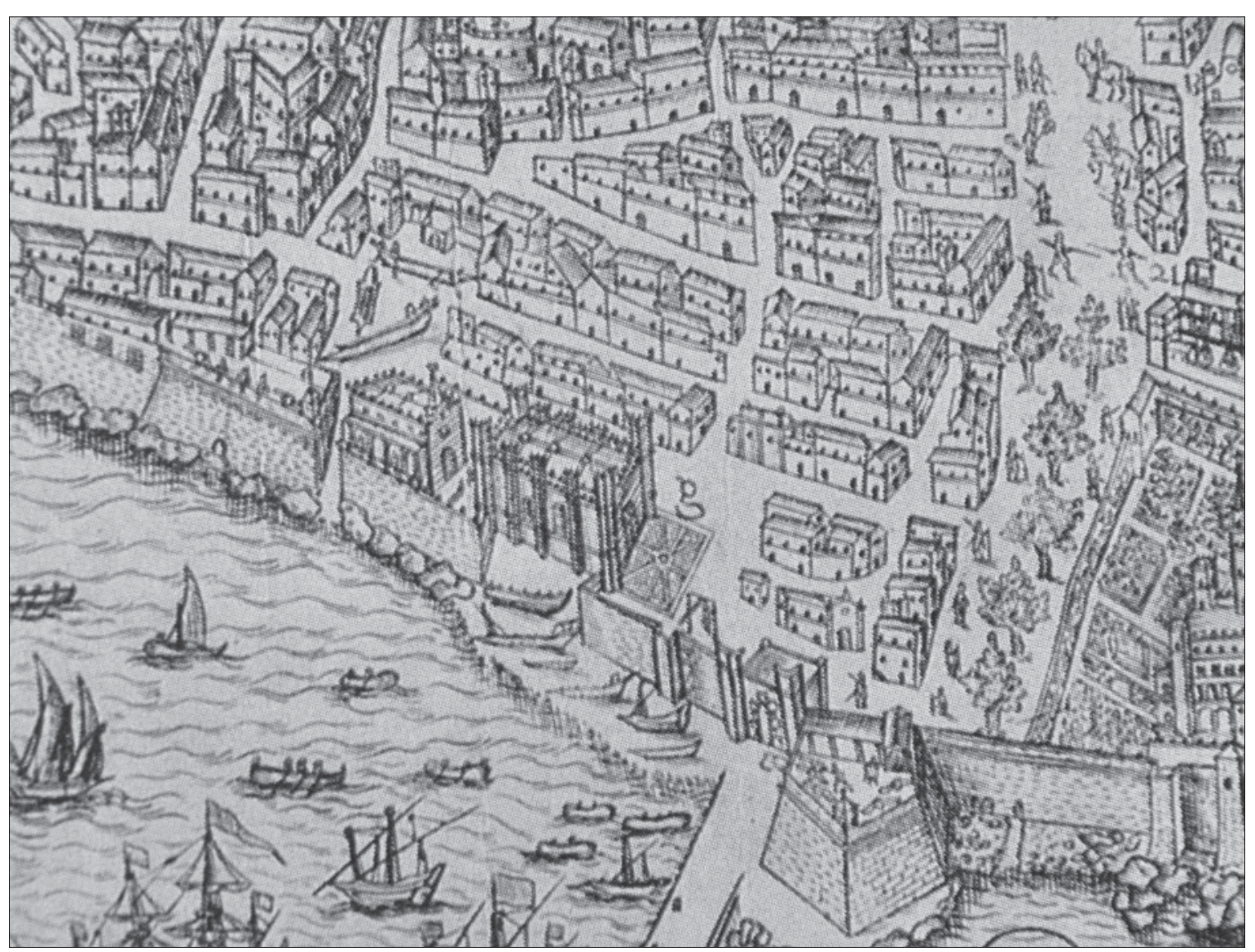

Figura 6.

Antoni Garau (dibuixant) i Antoni Company (gravador): plànol de Palma, 1644 (detall).

situades a l'Almudaina, que el 27 de març de 1427 va ampliar, per mitjà de compra, a la muller de Joan de Tagamanent, amb un altre immoble i corral. Les afrontacions ens permeten de saber que estava ubicat a l'actual carrer de Sant Sebastià, a la mateixa parròquia. Els hereus van alienar el complex per cent setanta lliures a favor del cavaller Pere Joan Fuster el Is de gener de $\mathrm{I}_{4} 62^{82}$. Certament, no era la residència habitual de l'arquitecte, que es trobava al carrer de l'Almudaina, avinent del carrer de Palau, aproximadament entre la desapareguda Can Berga «de Cort» i l'actual Can Oms. Aquesta era la casa que, l'any I456, Francesc i els seus germans aportaven com a fiança del dot de la germana Agnès, cent cinquanta lliures, una xifra no gens mòdica per a la filla d'un menestral, el triple del que solien aportar de mitjana les núvies dels picapedrers. Si, com era el cas, el dot no es feia efectiu ipso facto, calia presentar una garantia, com es va fer en aquest cas amb el domicili habitual i amb deu lliures censals que la mare rebia a Sóller. Però, d'això, no se'n pot inferir de cap manera una desfeta patrimonial. De fet, vuit anys més tard, els Sagrera van satisfer al cunyat el deute dotal -a més del retorn d'algunes quantitats prestades - transferint-li cent cinquan- ta lliures que els devia el solleric Bartomeu Frontera (sembla que es tracta de l'oncle matern de la núvia), d'acord amb les actes d'un procés que es dirimia a la cúria del governador de Mallorca ${ }^{83}$. És veritat que la família devia quaranta lliures de pensions censals pel camp anomenat «fossar dels jueus» - un antic cementeri de jueus, davant de l'hospital de Santa Caterina- ${ }^{84}$, però el gep no s'ha de magnificar. De moment, el mes d'agost de 1456 , els Sagrera consignaven al convent de dominics la mateixa quantitat sobre el crèdit que tenien contra els obrers de Santa Eulàlia - que llavors havia minvat a cent lliures-, però, el mes següent, decidien retornar la propietat als frares, segurament a causa de la impossibilitat de cobrar el crèdit. D'altra banda, sembla que tenien el solar arrendat, mal que el lloguer de vuit lliures anuals no compensava la càrrega censal ${ }^{85}$. De nou, si la ruïna era tan estrepitosa, per què els hereus de l'arquitecte no es van desprendre abans dels altres immobles, molt més valuosos? Tampoc no sabem què va passar amb el solar que mestre Guillem compartia amb Jaume Servera des del $1436^{86}$. El que sí que podem assegurar és que l'arquitecte disposava d'altres propietats i fonts d'ingressos. Així, el mes de maig de 
I457, el fill Francesc, en nom propi i en el dels dos germans que residien a Nàpols, venia a Guillem Vilasclar per dotze lliures un camp situat al camí de les Set Aigües, devers la carretera de Bunyola, carregat amb un cens de trenta-dos sous; entre els testimonis apareix el cosí Antoni Sagrera ${ }^{87}$. A més, l'any I 453 el monarca havia cedit a l'arquitecte l'usdefruit de setanta lliures anuals sobre els drets dels molins reials de la sèquia de Ciutat, un nou detall que confirma l'estimació que li professava el Magnànim, ja que li feia la mercè per voluntat pròpia («et de certa nostra sciencia et consulto nostro proprio motu et gracia speciali») $)^{88}$.

Sigui com sigui, disposem d'una font documental excepcional per mirar de comprendre millor el nostre personatge i d'interpretar de cap i de nou la qüestió de la seva bancarrota. Em refereixo, naturalment, al famós plet incoat contra el Col-legi de la Mercaderia ${ }^{89}$. No obstant la interpretació que ens n'ha ofert Maria Rosa Manote $^{90}$, crec que encara permet fer-ne lectures alternatives. Endemés, he de confessar que no comparteixo del tot l'anàlisi que en fa la collega i amiga Maria Rosa Manote - posem per cas, defensar a ultrança la «ingenuïtat» de l'arquitecte o passar en silenci informacions constructives de gran fet-, ni tampoc algunes de les conclusions que Gabriel Alomar i Gabriel Llompart, entre d'altres, han deduit d'aquell document - del poc que se'n sabia, val a dir-, com ara el maquiavellisme dels mercaders o, com he explicat abans, la ruïna absoluta del mestre. Ja puc avançar la conclusió principal sobre el personatge: un excel-lent arquitecte $\mathrm{i}$ un pèssim mercader.

Resumint, el plet l'inaugura la carta que, a precs de l'arquitecte, el rei Alfons dirigeix a la Mercaderia l'any I449. S'hi fa memòria dels antecedents $\mathrm{i}$ de les condicions del contracte signat l'any I426, on s'avaluava la feina en vint-i-dues mil lliures, excloses la fusteria i la serralleria. El problema, argüia el demandant, era que les despeses superaven el preu convingut, però sobretot que, per raó del retardament en la cobrança, s'havia vist obligat a manllevar doblers a un interès elevat:

[...] per com ell, dit mestre Guillem, contínuament hage treballat e vagat, ab diverses sclaus e familiàs seus en la dita obra, e conduits per lo dit temps a sou seu e dispesa molts e diverses mestres e laborants segons en aquella obra requerit, se és trobat haver cumplida la dita Lotge e haver acabat de destrohir tots sos béns, e assò tant per la dispesa que y ha feta en la obra, que és montada ultra les vint e dos mília liures, quant encare per diverses interesses que ha pagats, perquè ell havia de suplir als mestres e altres obrers e lavorants, e les pecúnies qui li eren assignades no les podie haver al temps degut, perquè li convenia pendre aquells diners a interesses, e de aquets interesses ha pagats una gran summa [...].

L'arquitecte exigeix tres mil lliures per compensar els perjudicis i, alhora, el monarca obliga els mercaders a resoldre l'afer en tres mesos ${ }^{91}$. Com he dit abans, serà el fill Francesc qui adduirà un error de pressupost per raonar la seva deman$\mathrm{da}$, fins arribar a un càlcul exorbitant: «que la dita obra si's fos continuada e acabada segons los dits pactes de la dita scarada haguera costat pus de trenta y sinch mília quatre-centes e vint lliures». Tanmateix, disposem d'una obra de referència que sembla indicar el contrari, que Sagrera feia una estimació més aviat a l'alça: la Gran Sala de Castelnuovo va ser contractada a finals de 1452 per dotze mil ducats, a raó de cent unces mensuals, sense comptar la pedra de Mallorca i de Pozzuoli, la fusta, la ferramenta, la calç i altres agatges, abans que el mes de març de 1454 es rebaixés la suma total a onze mil ducats, a més d'un salari de dotze ducats mensuals per al mestre - que sols va poder gaudir durant vuit mesos-, sis per a l'ajudant Joan Trescoll i vuit per a l'administrador Ramondello de Citellis. Encara que són obres heterogènies, permeten un parangó suficientment aclaridor ${ }^{92}$.

Com era d'esperar, la resposta dels mercaders fou negativa, al·legant raons de tipus jurídic - adduien que el manament reial atemptava contra les franqueses del Regne, bé que finalment n'acceptaren la legitimitat - i, el que per nosaltres resulta més interessant, de tipus constructiu: Sagrera havia suprimit «certes filades de alt e en certa manera», per la qual cosa, respecte al contracte, «haje feta la dita Lotge pus baixa de dues filades fins en tres, segons se pot veure a hull», una particularitat de gran importància que paradoxalment ningú no ha considerat. La queixa no és accidental, sinó que els mercaders la reiteren: «[...] que lo dit mestre Sagrera en prejudici dels capítols e pactes de la dita obra ha obmesos seguir les coses contengudes en los dits capítols, car devia fer la dita Lotge de certes filades de alt e en certa manera, la qual cosa no ha feta, e per conseqüent deu esmenar al dit Col-legi la quantitat per disminució e mancament de les dites filades tatxades [...]».

Si els mitjans, posats de cantell, fan 30,48 centímetres de fil, aproximadament ${ }^{93}$, vol dir que el Col-legi de mercaders es planyia d'una defalca de devers 60 a 90 centímetres en l'alçària de l'edifici, sempre amb relació a les condicions contractuals $-\mathrm{i}$ segurament a pactes verbals entre clients $\mathrm{i}$ arquitecte-, la qual cosa modificava substancialment l'esquema proporcional o, si més no, l'aparença dels alçats exteriors. Però, a més, si prenem en consideració el perímetre de l'edifici (prop de I40 metres) i la llargada de cada mitjà (80 centímetres), haurem de convenir que, si és
89. ARM, AA, XXXII-2171.

90. Maria Rosa Manote, «El contrato y el pleito de la Lonja...»; "L'escultura gòtica catalana...». Cfr. nota 6. La seva tesi doctoral incorpora una transcripció completa del plet.

91. El document original es pot consultar a ACA, Cancelleria, Reg. 2730, f. 133; 1449, 20 de gener. El rei encomanà l'afer al governador Berenguer d'Oms l'any 1450 i, quan aquest cessà en el càrrec, al nou governador Arnau de Vilademany i de Blanes (ACA, Cancelleria, Reg. 2918, f. 49; 1451, 23 de desembre). Atès que la demanda no va tenir efecte, el rei comminà l'any 1455 Joan Armadans, conseller i advocat fiscal del regne, a reobrir el procés, a instància dels hereus de l'arquitecte (ACA, Cancelleria, Reg. 2735, f. 93; 1455, 18 d'abril).

92. La gran sala napolitana té planta quadrada, de 26 metres per costat, és a dir, una superfície interior de $676 \mathrm{~m}^{2}$, mentre que la Llotja té planta rectangular, de 35,30 per 23,10 metres, aproximadament, i, per tant, una superfície de devers $815 \mathrm{~m}^{2}$. Ara bé, l'alçària interior de la sala de Castelnuovo és de 28 metres, mentre que la de l'edifici mallorquí és de devers 15,60 metres. El gruix dels murs de la Llotja és de 2,75 metres, aproximadament, mentre que el de la sala napolitana supera els 3 metres, si la planta que publica Alomar és correcta, cosa que no dubto. D'altra banda, la Llotja, dividida en tres naus per les bellíssimes columnes entorxades, està coberta per dotze voltes de creueria simple, a diferència de l'única i virtuosística volta estrellada de l'altra (com ha recordat Amadeo Serra, sols superada pel que fa al diàmetre, entre les cobertes contemporànies, per la cúpula brunelleschiana de la catedral de Florència). El contracte definitiu establia un preu per a l'obra napolitana de cinc mil lliures menys que el de la Llotja mallorquina, com a mínim.

93. Sobre aquestes mides, vegeu Javier Vellés, «De las máquinas de medir», dins F. Climent (coord.), La Lonja de Palma, Palma, 2003, p. 165-187: «Todas las hiladas son iguales con una precisión sorprendente. Midiendo unas cuantas de una vez en varios sitios y hallando promedios, concluimos que la altura de cada piedra era de $304,8 \mathrm{~mm}$. [...] Pero coincide exactamente con el pie marinero de $304,8 \mathrm{~mm}$.». L'autor —algunes afirmacions del qual són com a mínim discutibles - no hi afegeix que, a Mallorca, aquesta mesura (aproximadament 30 centímetres) fa referència al mitjà «de gruix d'emperador", d'ús força habitual -el mur de marès fabricat amb aquests mitjans rep el mateix nom. 
94. Gràcies a Agustí Frau (cfr. infra nota 98), se sap que, el 19 de març de 1451, Guillem Vilasclar contractava l'acabament dels finestrals per dues-centes vuitanta lliures: «totas las claravoyes e maynels sive corones qui s'an a fer en les sis finestres de la dita Lotge [...]», dues d'acord amb «la forma o mostra» lliurada pel mateix Vilasclar i les quatre restants, com les havia començades Guillem Sagrera. vertadera l'asserció dels clients, hi manca molta pedra (devers 175 mitjans per filada). En tot cas, no hem de fer cas de la gruixa dels murs inferiors (aproximadament 2,75 metres), perquè l'àtic on es desplega la pseudogaleria de solana té el gruix d'un sol mitjà.

En definitiva, calia passar comptes per menut, una operació que facilitaven els corresponents quinze llibres de comptabilitat guardats pel Collegi. Llavors, Sagrera, representat pel notari Jaume Riera, aportà un dels seus cavalls de batalla: no sols havia treballat de mitjana amb deu homes a jornals sencers, de sol a sol, sinó que l'equip havia assumit mig jornal més, és a dir, sis hores suplementàries entre matinada $\mathrm{i}$ capvespre, tots els dies feiners, de novembre a febrer. Això exigia la declaració de testimonis, per començar el d'alguns dels picapedrers que hi havien treballat, com ara Cristòfol Vilasclar («stech per gran temps ab lo dit mestre Guillem Sagrera e ab aquell ha après lo offici e ha treballat per molt gran temps en la obra de la dita Lotge»), Andreu Terriola (hi laborà vuit anys), Miquel Sagrera (hi treballà més de dotze anys, però, quan començà la feina, «ja eren fets los portals, finestres e la obra ben alta [...]») i Antoni Costa (que hi va feinejar vuit anys i tracta de compare l'arquitecte, és a dir que un dels dos era padrí de fonts d'un fill de l'altre). El sacrifici fet pel taller, volia dir el demandant, valia més de dues mil lliures. La resposta del Colllegi fou contundent i l'al-legat, estrictament tècnic: redreçar la «diformitat» causada per Sagrera suposava un mínim de sis mil florins - entenent que la meitat hauria de compensar la pedra volatilitzada-, ja que el mestre havia bastit una llotja «fora de mesures». Es torna, doncs, al tema abans exposat de la desaparició en alçària de diverses filades de pedra. A més a més, en el moment de la partença cap a Nàpols, restava molt per fer. Calia acabar sis finestres - és a dir, totes les de la planta baixa - i dos portals amb «claraboies» o traceries - encara que aparenten grans finestrals, són els que s'obren a la façana de tramuntana-, una obra que no es podia executar per menys de mil florins ${ }^{94}$; enllestir el paviment amb pedra de Santanyí, la qual cosa suposava una despesa complementària de cinc-centes lliures, no obstant disposar de pedra tallada a propòsit per Cristòfol Vilasclar i Antoni Sagrera entre I439 i I440; afegir alguns detalls a les torres i a la galeria de finestres del coronament, una feina que els mercaders avaluaven en trescentes lliures, i, encara, obrir un encaix o forat per al rellotge, obra per la qual el mestre havia cobrat a part setanta-cinc lliures.

Però, per si no n'hi havia prou, els clients es queixaven de dues mancances greus, que la historiografia ignora. Primer, que Sagrera no havia tancat l'edifici amb un terrat («terrada plana»), com s'havia fet constar en el contracte, sinó amb «ayguavessos», amb la qual cosa s'estalvià les tres filades de pedra a l'entorn $\mathrm{i}$ - repeteixo jo - alterà les proporcions i l'aspecte exterior de l'edifici. De l'interior, en canvi, no hi ha cap queixa. El text és inequívoc:

E de altre part havia a cobrir lo dit mestre Guillem la dita Lotge a terrada plana, en la qual haguera hagudes metre tres filades de pedra al entorn més que no ha meses, e ell ha cuberta la dita Lotge ab los ayguavessos que té sens igualar aquella, de que ha defalcades les dites filades, les quals ab la dita terrada pujarien a mil florins d'or. E d'altre part ha a fer en la dita terrada trespol, qui costaria trescentes lliures.

En conseqüència, la modificació suposava un desajust comptable de mil florins d'or, com a mínim. Si es tractava d'un ardit de l'arquitecte per fer bossa o, en canvi, d'una solució fundada en raons tècniques o estètiques, no ho podem saber, ara per ara, però almanco és inqüestionable que Sagrera va optar per una coberta amb aiguavessos. La manca de detalls ens obliga a ser prudents; per exemple, sobre l'angle d'inclinació dels aiguavessos, potser molt agut, potser molt obtús, o, si feien curvatura, sobre llur grau de declivi. De totes maneres, s'intueix que la minva de dues o tres filades de pedra al voltant del perímetre superior i l'alteració de la coberta plana són canvis entrelligats. Això no obstant, no podem conèixer, de moment, la formalització concreta del sistema elegit per Sagrera: ni l'estructura de suport, si és que no pensava en una coberta trespolada, com li exigien els clients, ni els materials de cobertura, ni si aquesta construcció cobria tota la solera del terrat o únicament un sector, ni tampoc les vicissituds constructives - o desconstructives - experimentades ulteriorment. El que es dedueix de les visures efectuades l'any i68 I per dos grups d'experts és que, llavors, l'edifici disposava d'un terrat: uns mestres aconsellen «que's desfasse el trespol de la terrade» i, un cop examinat l'extradós de les voltes, «que se enretjol», mentre que els altres demanen que «per més custòdie y conservasió del edifici se coprís de teulada, ab uns pilars de cuadrats de dos pams de cuadro, allà on serà menester, cubert de cuatre aygovessos [...] açò se entén reservant tot lo espai que's podrà per un passejador al contorn", és a dir, com es va fer i s'ha mantingut fins a l'actualitat. D'altra banda, les primeres representacions gràfiques a vista d'ocell de l'edifici ens permeten de conèixer l'aspecte de la coberta a la primera meitat del segle xvir. En particular, és digne de fiança el famós gravat d'Antoni Company, datat l'any I 644 i que, com revela la mateixa representació, reprodueix la ciutat «accuratissime delineata» per Antoni Garau, prevere i matemàtic. El plànol mostra la 


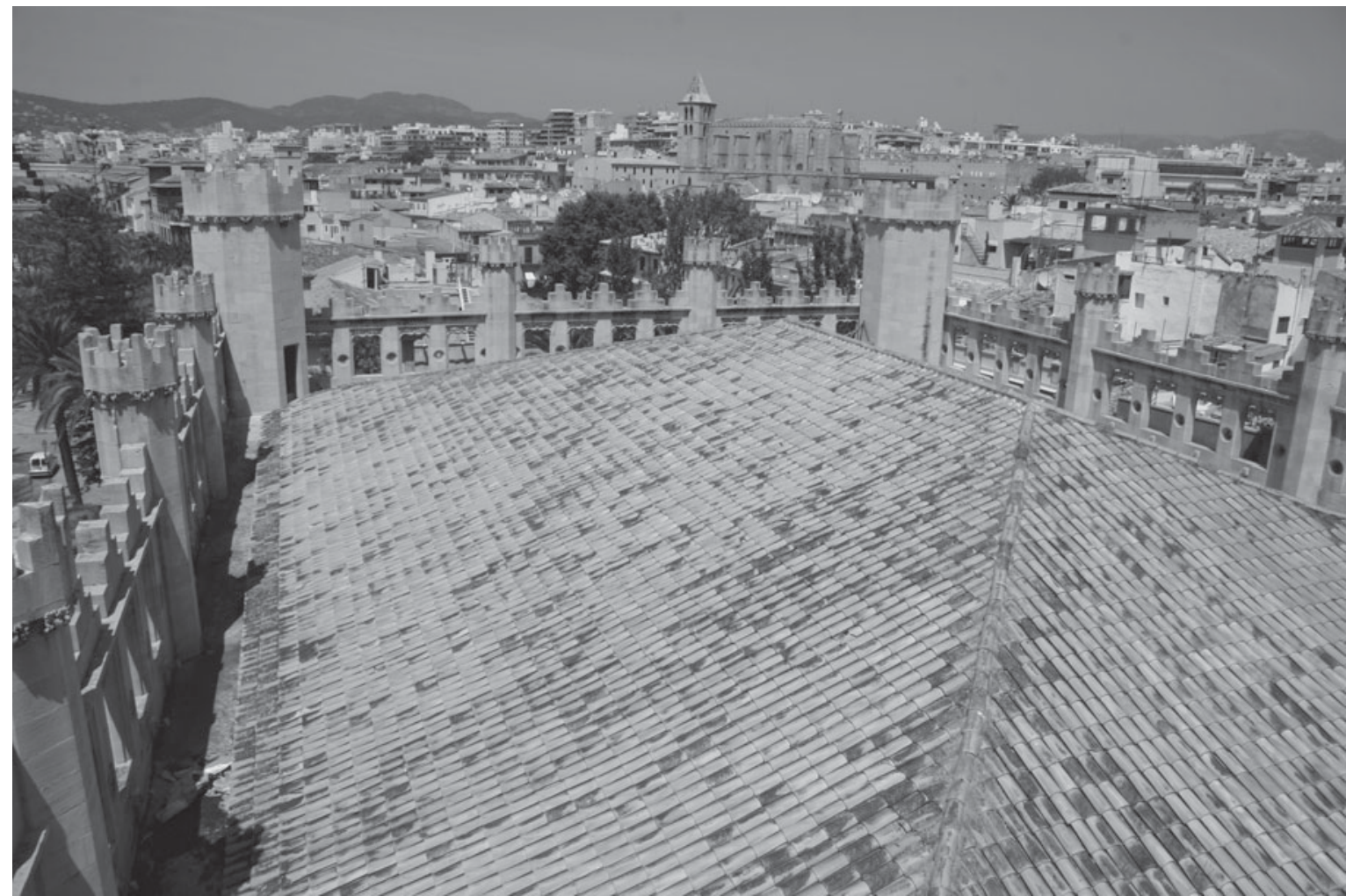

95. Agustí Frau, «La Lonja de Palma», núm. 29, p. 5 (cfr. infra, nota 98).

96. Guillem Forteza, «El cicle arquitectònic de les nostres llotges medievals», Revista de Catalunya, XIV (1934), p. 221248 ; reproduit a Guillem ForTEZA, Estudis sobre arquitectura $i$ urbanisme, 2 vols., Abadia de Montserrat, 1984, vol. 2, p. 7699, en particular, p. 94.

97. Catalina Cantarellas, «La Lonja de Palma: intervenciones y propuestas ochocentistas», Mayurqa, 22 (1989), p. 719-732. La posició de Rubió va enardir un estol de detractors, però també qualque defensor, com ara Bartomeu Ferrà.

Figura 7.

Llotja de Palma, terrat cobert. Foto de Margalida Morey.

Llotja coberta amb terrat, però no necessàriament pla, atès que s'hi distingeixen un carener central longitudinal i tres carenes de tremujal transversals. També s'intueix que eren carenes de pedra o de reble, sense recobriment de teules. Aquesta mena d'espina formada per carenes ortogonals delata l'extradós de les vuit voltes de creueria de les naus laterals, mentre que el carener recorre l'eix de les voltes de la nau central - és a dir, ens marca l'espinada d'aquestes voltes - $\mathrm{i}$ les carenes menors s'afileren amb els respectius pilars helicoïdals de l'interior. Tot i així, si volem fer cas dels documents esmentats, no podem atribuir aquesta idea a Guillem Sagrera, sinó, com a alternativa més plausible, als dos mestres que el mes d'agost de I446 contractaren la continuació de la fàbrica, Guillem Vilasclar i Miquel Sagrera, els quals assumiren, entre altres coses, «tota la obra que fer e acabar se deu en la terrada demunt la dita Lotge, segons la mostra, axí de pedre, cals, morter, reble e totes altres coses com de mans fassedores [...]» ${ }^{95}$.

Per tant, és un fet que el debat sobre la solució original de la coberta externa de la Llotja està tancat en fals. I és que l'última paraula encara es deu a l'admirat Guillem Forteza, a qui potser caldrà impugnar:

Vull fer notar una altra singularitat prodigiosa de la Llotja de Palma, i és el coronament de les seves façanes. De cap manera no puc creure que la cresteria decorativa de la Llotja sigui, com algú ha volgut suposar, l'encintat d'un altre pis o planta utilitzable, o el suport dels vessants d'una teulada futura. La tradició de la coberta de la casa gòtica mallorquina és, rigorosament, la «terrada» amb les seves gàrgoles de desguàs. No negaré la possibilitat que Sagrera pensés a protegir les voltes pètries amb una segona coberta de teules (com la que avui existeix, per cert, molt ben disposta), o una porxada com les que després del segle Xvi esdevingueren sistemàtiques en els palaus mallorquins (manllevant-ne el motiu a la mateixa Llotja); afirmaré, però, que el mensurat $i$ el coronament $i$ cresteria que ens ocupen són una estilització finíssima de les barbacanes i rondes militars: una humanització decorativa de l'emmerletat de les fortificacions medievals ${ }^{96}$.

La invectiva de Forteza anava dirigida contra Joan Rubió i Bellver i el seu projecte de restitució de l'aspecte «original» de la Llotja sagreriana, publicat l'any $1905^{97}$. Però, al marge de les formes que articulen la reconstrucció idealista i ahistòrica, à la Viollet-le-Duc, de Rubió, és necessari reobrir la discussió sobre el tipus de coberta exterior de l'edifici, a partir de la nova lectura de la documentació i d'un intent de desxifrar la lògica constructiva de la galeria de finestres del corona- 
98. Agustí Frau, «La Lonja de Palma", BSAL, I (1885-1886); núm. 14, p. 1-5; núm. 15, p. 3-4; núm. 16 , p. $2-5$; núm. 17 , p. $1-2$; núm. 18, p. 1-3; núm. 19, p. 5-7; núm. 20 , p. 4-5; núm. 21 , p. 3-4; núm. 22 , p. $4-6$; núm. 23 , p. 6-7; núm. 25, p. 3-6; núm. 29, p. 5-6, i núm. 32, p. 10-13. ment. Certament, sense altres fonts d'informació, fóra temerari reconstruir el pensament arquitectònic de Sagrera i, en general, el dels constructors medievals, però també se'm fa difícil d'acceptar que l'única explicació plausible per a les dites finestres sigui, com proposava Guillem Forteza, la funció que ara en diem "estètica».

Recapitulant, els clients volien un edifici amb alçats exteriors més alts que els actuals - entre 60 i 90 centímetres, poc més poc menys - i cobert amb un terrat trespolat, mentre que Sagrera va optar per rebaixar-ne l'alçària exterior i tancarlo amb una coberta amb aiguavessos. En canvi, totes dues parts estaven d'acord amb la traça de les finestres del coronament («e que lo mur qui incircuirà tota la Lotge dalt sia ab claraboyes»). És indefugible la formulació de noves hipòtesis, partint del supòsit que l'augment de l'alçària de l'àtic en seixanta centímetres, com a mínim, posant els maresos a sota del finestratge actual -és a dir, suposant que les finestres havien d'estar més amunt del que ara es veuen-, possibilitava l'existència d'un pis a guisa de golfes. S'hi havia previst un terrat pla a sobre? o, com volia Guillem Forteza $\mathrm{i}$ tothom sembla haver acceptat sense reserves, la insòlita cresteria de finestres compleix funcions estètiques i compositives, però no pràctiques? Amb un terrat pla dalt del pis ara inexistent, pis que hagués badat a l'exterior mitjançant les finestres presents, els merlets adquireixen també un nou sentit, fer servei d'ampit o barana, a més d'embellir l'edifici. Però també caldria plantejar de nou el problema irresolt de les gàrgoles: funció, datació, autoria, etc. En definitiva, ara que finalment s'ha endegat la restauració de l'edifici, no es pot defugir una resposta raonada als problemes que suscita una interpretació inèdita de la documentació exhumada; també serà qüestió d'esbrinar la història constructiva de l'edifici al llarg dels dos segles posteriors a la mort d'en Sagrera i d'interpretar novament l'abast de la reforma efectuada a finals del segle Xvir.

El segon greuge que al-legaven els mercaders repercuteix dramàticament en el catàleg escultòric del mestre: mancaven cinc imatges per un valor global de dos-cents florins. Podem debatre ad infinitum quines són aquestes obres, però tot, és a dir, tant el preu com el nivell de qualitat de l'execució, permet defensar que són les dues imatges que havien d'ocupar els tabernacles de les torretes centrals de les façanes de tramuntana i migjorn, tal com hi apareixen (idealment?) restituides en els famosos gravats de F. Jordán ( $18 \mathrm{I} 3$ ), segons originals d'I. González Velázquez (I8 I3), la figura que havia de presidir el mainell de la porta de llevant $i$, per una lògica elemental, almanco dos dels quatre sants dels tabernacles cantoners - robat l'any i 885 el sant Nicolau. La solució no és fàcil, perquè encara no sabem si es va com- pletar el primitiu programa escultòric ni per quin motiu es va afegir l'espectacular àngel del timpà de la porta de llevant, en substitució de la Verge amb el Nen, que fou desplaçada a la façana oposada. A més, foren realment cisellats els dos àngels de les façanes de tramuntana i migjorn? Hem de creure que sí, si fem cas dels gravats de l'esmentat Jordán - que, a més a més, hi suma una altra estàtua sota el tabernacle de la porta principal. En canvi, el gravat de Melcior Umbert que reprodueix l'edifici per al Panorama de las Islas Baleares, d'Antoni Furió (I 840), presenta un àngel a la façana nord, però no l'escultura sota dosser de la porta principal, mentre que, en el gravat corresponent que il·lustra el Die Stadt Palma, de l'arxiduc Lluís Salvador (I 882), han desaparegut les imatges dels tabernacles de les façanes de llevant $i$ tramuntana. De moment, santa Caterina i santa Clara susciten poc entusiasme entre els especialistes, la Mare de Déu del portal de ponent atreu més adhesions i l'atribució del Baptista assoleix un consens majoritàriament favorable a l'autografia del mestre. Tot i així, a parer meu, si el sant Joan i la Mare de Déu es volen adjudicar a Sagrera, no es pot fer sense reconèixer-hi la intervenció considerable de colllaboradors. Dit això, aquest debat exigeix més espai i reflexió de la que ara se li pot dispensar. Mentrestant, deixem que, aquest sí, l’Àngel de la Mercaderia -o, si se'm permet la boutade, aquelles fantàstiques «ales amb àngel»-somrigui complagut de la seva autografia.

Tot plegat, després de moltes controvèrsies, la Mercaderia calculava que l'obra deixada inacabada per Sagrera superava els tres mil florins, baldament degué inflar el càlcul, fins a duplicar-lo en alguna ocasió («e los mancaments de la dita obra munten més de set o vuyt mília lliures [...]»). A la fi, l'any I533, reconeixia que devia «magnis quantitatibus» a l'arquitecte, mal que acceptà de pagar als hereus només mil vint-i-cinc lliures. Dels comptes principals, n'hem d'excloure el contracte estipulat entre Sagrera i dos colllaboradors, just abans de partir cap a Itàlia. En efecte, com va documentar Agustí Frau ${ }^{98}$, el I 3 d'agost de I446, l'arquitecte va subcontractar l'acabament de les obres amb Guillem Vilasclar i Miquel Sagrera a canvi de sis-centes setanta-cinc lliures, a més de la pedra tallada o sense tallar que hi havia ja a l'edifici: «fer e acabar totes les obres qui s'an a fer en las torres, bestorres, finestratges, merlets, caragols [...] e axí matex tota la obra que fer e acabar se deu en la terrada demunt la dita Lotge [...]». I tampoc no hi interferia una partida independent, de la qual estem informats gràcies al mateix Agustí Frau. I és que, el 7 de setembre de I444, Sagrera reclamava a la Mercaderia millores introduïdes a la traça original per valor de mil nou-centes quaranta-dues lliures, si bé el 3 I de maig següent s'avenia a cobrar-ne mil vuit-centes cinquanta. De 
la relació d'àpoques publicada per Agustí Frau es pot inferir que les va rebre i, de fet, el fill Francesc després no les va reivindicar. Repassats els comptes, els clients asseguraven haver pagat vint-i-dues mil vuit-centes trenta lliures (incloses, però, les sis-centes setanta-cinc lliures assignades a Guillem Vilasclar i Miquel Sagrera per acabar l'obra) i que, com a molt, devien al mestre cent onze lliures i escaig99. Davant l'evidència, Francesc Sagrera hagué de reconèixer que el pare havia rebut vint-itres mil vint lliures. Per tant, quin era el problema real? Doncs que l'arquitecte, a més d'esmerçar vint-i-tres mil cent setanta lliures en l'obra - de manera que, ben mirat, Col-legi i mestre restaven més o manco parells-, havia gastat dues mil duescentes cinquanta lliures en mitjos jornals - ja he dit que l'argument es convertia en un cavall de batalla decisiu - i nou-centes quaranta-vuit lliures per pagar interessos per préstecs manllevats a diferents particulars. La xifra exacta demandada pujava a tres mil tres-centes quaranta-vuit lliures $($ I $50+2.250+948)$.

En veritat, l'origen de la tragèdia no era el sistema de pagament, com massa vegades s'ha repetit, perquè Sagrera mai no se'n va queixar, sinó la temptació de voler assumir la gestió directa del dret del victigal o dineret del moll - un diner per lliura de mercaderia entrada o sortida del port de Ciutat. És cert que l'arquitecte havia d'avançar cinc-centes lliures anuals en l'obra, però el primer any va cobrar-ne mil cent com a anticipació (el mes de març) i nou-centes trenta-cinc de la primera anualitat (el mes de setembre), de manera que no partia de zero. Els doblers provenien de l'esmentat impost, que s'adjudicava per subhasta. Primer, el Col·legi es reservà cent cinquanta lliures, però, des del I429, les augmentà a dues-centes, sempre per fer front a despeses peremptòries; per exemple: «pro reparando et aptando la mora de la lanterna del faro de Portopí et pro edificando sive construendo predictam lanternam in dicta mora». El cas és que Sagrera, potser mal aconsellat o per desconfiança envers els clients o per una legítima ambició comercial, va reeixir a obtenir l'administració del victigal diverses vegades (I430, I43I, I432, I433, I434), fins $i$ tot arribant a duplicar ocasionalment la mitjana del preu d'adjudicació (2.30I lliures, l'any I 433; 2.3 I 2 lliures, l'any I 434). Llavors, Sagrera en transferia al Colllegi la fracció corresponent $\mathrm{i}$ en retenia la resta per compensar el pagament anual de les obres. El repte era, naturalment, rescabalar els doblers invertits. Però en aquest afer, allò que manava era la conjuntura del comerç marítim ${ }^{100}$. I Sagrera no se'n va sortir. El Col-legi de mercaders li ho deixà ben clar: «E si lo dit mestre Guillem ha perdut arrendant e comprant lo diner de la mercaderia, açó stà a son càrrech, car si hagués guonyat fóra a son profit» ${ }^{101}$. Del risc assumit per Sagrera, n'eren ben conscients els seus clients - deixant de banda que, naturalment, s'aprofitaven d'una subhasta a l'alça-, i aviat degueren descobrir el perill que l'obra restés aturada. Això explica que el Col-legi volgués canviar els pactes: a partir del I433, s'arribà a un acord per mitjà del qual el mestre havia de rebre una quantitat fixa cada any: mil dues-centes trenta-vuit lliures. A la vegada, l'arquitecte, escalivat, des de l'any I 435 no va participar més en la subhasta. Li prenen el relleu mercaders poderosos, i la majoria d'origen convers: l'any 1435 obté el victigal Tomàs Pardo per mil quatre-centes lliures; l'any següent, Pere Pardo, per mil set-centes lliures; els anys successius, Gabriel Salvà, Jaume de Pacs, Antoni Salt, Joan Marí, Daniel Pardo, Pere Morro, etc. És llavors quan Sagrera es veu obligat a endeutar-se, sempre impetrant el suport del Col-legi de la Mercaderia com a fiador. I, així, l'arquitecte es converteix en censalista de Pau d'Olesa per quatre-centes lliures (si bé els primers censataris havien estat els hereus de Ferrer de Comelles), de Joanot de Quint per dues-centes lliures, dels fills i hereus de Nicolau de Quint per dues mil tres-centes lliures (suma de cinc censals diferents), d'una dona Bricassa per cinquanta lliures, d'una dona Garcia per cinquanta lliures més, de Pere Martí per cent lliures, de Joan Vicenç per cent lliures més i de mossèn Rovira per dues-centes lliures. Tot plegat suma tres mil quatre-centes lliures i si hi afegim els interessos al vuit per cent, més el que no havia pogut rescabalar de la seva gestió del victigal, heus ací la desfeta financera del felanitxer. No em sembla casual que Francesc Sagrera reclamés als mercaders tres mil tres-centes quaranta-vuit lliures, una quantitat sospitosament semblant a la hipoteca en censals acumulada per son pare.

No voldria deixar de reproduir una cita incorporada al plet. Data de l'any i 505, quan Francesc Sagrera reprèn el litigi, que havia estat posposat arran de l'absència prolongada de l'illa del mateix pledejant, de les torbacions bèl-liques a Catalunya $i$ de diverses epidèmies de pesta. Forma part de l'al-legat presentat pel notari Francesc Sans (inspirat pel seu client?) a la cúria del governador i és potser la més bella lloança que mai s'hagi escrit del nostre arquitecte i de la seva Llotja:

In hac autem civitate nemo est qui nesciat hoc celeberrimum opus de quo loquimur mira arte prespicacique ingenio fabricatum constructumque fuisse per peritissimum virum magnificum Guillelmum Sagrera et nominem fugit quin publica fama predixerit peccunias per dictum Collegium sibi traditas ad perficiendum tam insigne tamque sumptuosum opus [...].

Un altre tema que exigeix més atenció és l'activitat de Sagrera al Principat, no debades va desplegar la meitat de la seva carrera en territori
99. En el plet, s'hi detallen els pagaments, de manera que la incompleta relació publicada per Agustí Frau ha esdevingut obsoleta.

100. Sobre aquesta qüestió, vegeu, per exemple, Pau Cateura, «Obras públicas en tiempo de crisis (Mallorca, 1400-1450)», Mayurqa, 23 (1996), p. 31-42.

101. ARM, Protocols, 2506, f. 75; 1449, 17 d'agost: Antoni Sagrera, mercader, fill i procurador de Guillem Sagrera, d'acord amb el nomenament fet davant el notari Andreu Afelatzo de Nàpols el 28 de març de l'any anterior, ratifica Pau Borrell, ciutadà de Mallorca, com a procurador per recuperar 95 lliures del Col-legi de la Mercaderia sobre el victigal corresponent a l'any 1430. A canvi, si obté èxit, li cedeix 45 lliures. 
102. Joan VAlero, «Acotacions cronològiques i nous mestres a l'obra del claustre de la catedral", D’Art, 19 (1993), p. 29-41.

103. ACB, Notarial, vol. 271; 1401, 8 de gener; AHPB, 146/13; 1429, 15 de desembre.

104. AHPB, 123/2; 1422, 13 de març.

105. AHPB, 76/1; 1402, 1 de juny; AHPB, 145/1; 1421, 25 d'agost; AHPB, 154/7; 1433, 15 d'octubre. També trobem el llinatge Sagrera a Lleida, com en el cas del mercader Pere Arnau Sagrera (AHPB, 204/3; 1461, 7 de juliol), a Sant Salvador de Breda (ACB, Notarial, vol. 423; 1409, 29 d'octubre) i entre els batlles reials d'Igualada (vegeu Joan CRUz, «Batlles i oligarquies urbanes (Igualada, 1400-1419)», Pedralbes, $13 / 1$ (1993), p. 393 399).

106. Maria Rosa Terés, «Les obres de la catedral de Barcelona $i$ la intervenció de Francesc Marata, un escultor del gòtic internacional», dins A. Cubeles i $\mathrm{R}$. GRAU (coord.), El procés urbà i la identitat gòtica de Barcelona, Barcelona Quaderns d'Història, 8 (2003), p. 201-231.

107. Marià CARbonell:; «Marc Safont (ca. 1385-1458) en l'arquitectura barcelonina del segle xv. Documents per a un esbós biogràfic», Estudis Històrics $i$ Documents dels Arxius de Protocols, XXI (2003), p. 181-225.

108. P. Ponsich, Le palais des corts et la croix ronge française, 1423-1970, Perpinyà, 1970. Agraeixo la referència bibliogràfica a l'amic Julien Lugand.

109. Segons els seus protocols, abans d'anar a Mallorca, el notari passà per Tarragona i Santes Creus. És evident que deixà la cort napolitana a la mort del Magnànim, l'any 1458. En un testament de l'any 1450, nomenava hereu el gendre Bernat Far, notari de Mallorca (ARM, Protocols, P-452).

\section{ARM, Protocols, 2578.}

111. ARM, Protocols, 2579; 1457, 3 de maig. Rafel Tomàs deu ser el mateix artista que l'any 1463 contractava, juntament amb Guillem Martí, la dauradura del retaule major de Sant Jaume de Perpinyà i, set anys més tard, la fabricació i la pintura del vitrall central del cor de Sant Mateu de la mateixa ciutat. Vegeu Marcel Durliat, Arts anciens du Roussillon, Perpinyà, 1954; repr. per J. Gudiol i S. Alcolea, Pintura gótica catalana, Barcelona, 1986, p. 202. La personalitat de Pagano és més coneguda, perquè és un dels pintors que el cardenal Roderic de Borja emmenà a València per decorar al fresc l'absis de la catedral. L'any 2004, s'ha pogut recuperar una part del conjunt, els espectaculars àngels músics de la volta, obra de Paolo català. S'ha documentat una puntual intervenció en les obres del claustre de la catedral de Barcelona. Si, per un costat, el baix salari (quatre sous) i la cronologia (de gener a març del I 432) poden fer dubtar de la identificació del mestre -aquesta és l'opinió de M. R. Terés i Joan Domenge-, per l'altre costat, sembla que la vulgui confirmar l'aparició simultània d'alguns membres del clan Vilasclar (Guillem, Cristòfol i Joan, entre I43 I i I 432) i altres manobres del llinatge dels Sagrera (un Simó i un P. Sagrera) ${ }^{102}$. Dit això, s'imposa la cautela, ja que el llinatge Sagrera no era infreqüent a Barcelona, com ho palesa l'existència d'un Guillem Sagrera, mercader ${ }^{103}$; d'un Antoni Sagrera, barquer ${ }^{104}$, i d'un Bernat Sagrera, paraire de llana, i el seu fill homònim, mercader, contemporanis del nostre ${ }^{105}$. Ara bé, una primerenca estada barcelonina de l'artista el podia haver posat en contacte amb l'ambient renovador que es respirava a l'obrador catedralici. Per exemple, gràcies a Maria Rosa Terés, ara coneixem prou bé l'activitat de Francesc Marata, documentat a Barcelona entre $\mathrm{I}_{3} 82$ i I4I4/I7, i, en particular, com a novetat inestimable, la labor desplegada a les ordres directes de Claus Sluter a Dijon, entre 1389 i I39 I ${ }^{106}$. No podem, en tot cas, limitar la recerca de l'entroncament estilístic de Sagrera a terres borgonyones. En aquest sentit, resulta molt suggestiva la perspicaç recerca de Joan Domenge, que ha analitzat la relació de Sagrera amb l'arquitectura de la França meridional. D'altra banda, crec haver demostrat definitivament que Rotllí Gautier (o Vauter), el soci de Sagrera a Perpinyà - un mestre que entre I 432 i I 435 resideix a Barcelona, encara que dirigeixi la fàbrica de la seu de Girona, i entre I436 i I44I, a Lleida - era germà del mestre Carlí que, l’any I 408, traçà el projecte definitiu del portal major de la catedral barcelonina - $\mathrm{i}$ potser el mateix que, l'any I439, era un dels mestres majors de la catedral de Sevilla ${ }^{107}$. Llavors, atès que Carlí $i$ Rotllí eren oriünds de Rouen, caldrà plantejarnos si Sagrera s'interessà per característiques específiques del gòtic normand més actualitzat, com ara l'atapeïment ornamental amb complicades traceries i la revalorització de l'escultura, a la manera de la façana sud del creuer de la catedral de Rouen. Tanmateix, les tres arcades gòtiques del pati del palau de les Corts de Perpinyà, obrades per Rotllí entre I 424 i I 427 , fan patent la immensa superioritat de Sagrera ${ }^{108}$. I caldrà insistir en les analogies de l'arquitectura del mallorquí amb models d'Arnau Bargués. Que Sagrera va estudiar amb atenció la sala capitular de la catedral de Barcelona, em sembla evident - sense menysprear altres models adduïts per Amadeo Serra, entre d'altres, per explicar la coberta de la gran sala de Castelnuovo-, però també la composició de les façanes de la Llotja evoca obstinadament solu- cions barguesianes, començant per la façana de la Casa de la Ciutat de Barcelona - grans finestrals de traceria calada, articulació horitzontal amb motllures discontínues, àngel monumental de Pere Sanglada-, i, d'una manera més general, el tipus de façana que, en alguna ocasió anterior, he anomenat «de traceries», una alternativa innovadora a la tradicional façana «de coronelles», que Bargués sembla adoptar a partir d'exemples de l'edilícia religiosa, en paral-lel -i potser amb independència- a uns altres arquitectes del nord d'Europa. Es comprèn que l'any i 54I la Llotja cridés l'atenció de l'emperador Carles, que no reconeixia el caràcter civil de la tipologia: $« Y$ acaminant a la volta de Lonja, veent lo objecte del edifici de aquella, demanà si era yglesia».

Pel que fa a Nàpols, no puc aportar cap notícia que millori el coneixement de la biografia ni de l'obra de Sagrera, però ho puc compensar amb alguns apunts sobre diversos artífexs contemporanis del mallorquí. I és que es poden obtenir algunes notícies historicoartístiques dels fragmentaris protocols del notari Joan Castell, conservats a l'ARM. Oriünd de Tarragona, Castell va ser jutge ordinari de la cúria reial de Nàpols, abans d'instal-lar-se a Mallorca l'any I459 per exercir-hi de notari ${ }^{109}$. Hi trobem, per exemple, l'àpoca signada el 28 d'agost de 1458 per Anellus dell'Abbate, pintor de Nàpols, als curadors de l'heretat de Joan Dasiu, escrivà de porció, per haver pintat un escut, un elm i una cimera; hi apareix com a testimoni un tal Nardus Papaletra, pintor habitant a la mateixa ciutat ${ }^{110}$. O bé la constitució, l'any I 457, d'una companyia - mal que la pèrdua del document, llevat de l'encapçalament, impedeix oferir-ne més detalls - formada pels pintors Rafel Tomàs de Barcelona i els napolitans Jacopo Barreta, Paolo Burriello i Francesco Pagano $^{111}$. Entre les mateixes notes, també hi apareixen els noms de fusters valencians (Pere Terrades, Bartomeu Crespo, Pere Çamora, Vicenç Mateu i Maties Falcó, aquest últim «de domo» del rei) i catalans (Antoni Redó de Perpinyà, Gabriel Estrada, Joan Orriols), a més de Joan de Borbas i Miquel Pérez - també fuster del rei-, de qui no se'ns facilita l'origen, possiblement aragonès. Les dates van de 1452 a I457. L'abundància de fusters hispans respon a una demanda explícita del monarca. Alguns d'aquests noms (Pérez, posem per cas) eren coneguts, gràcies a les recerques sobre Castelnuovo, ja clàssiques, de C. Minieri Riccio i Riccardo Filangieri di Candida.

Així mateix, el notari Castell recull una àpoca de l'i de setembre de I459, per la venda d'una esclava, signada per Andreu Baco [sic], àlies Jacomart, de la ciutat de València, que cal identificar amb un dels germans del famós pintor Jaume Baçó. Mitja dotzena de documents fan referència als Gomar, fusters i imaginaires molt actius a 


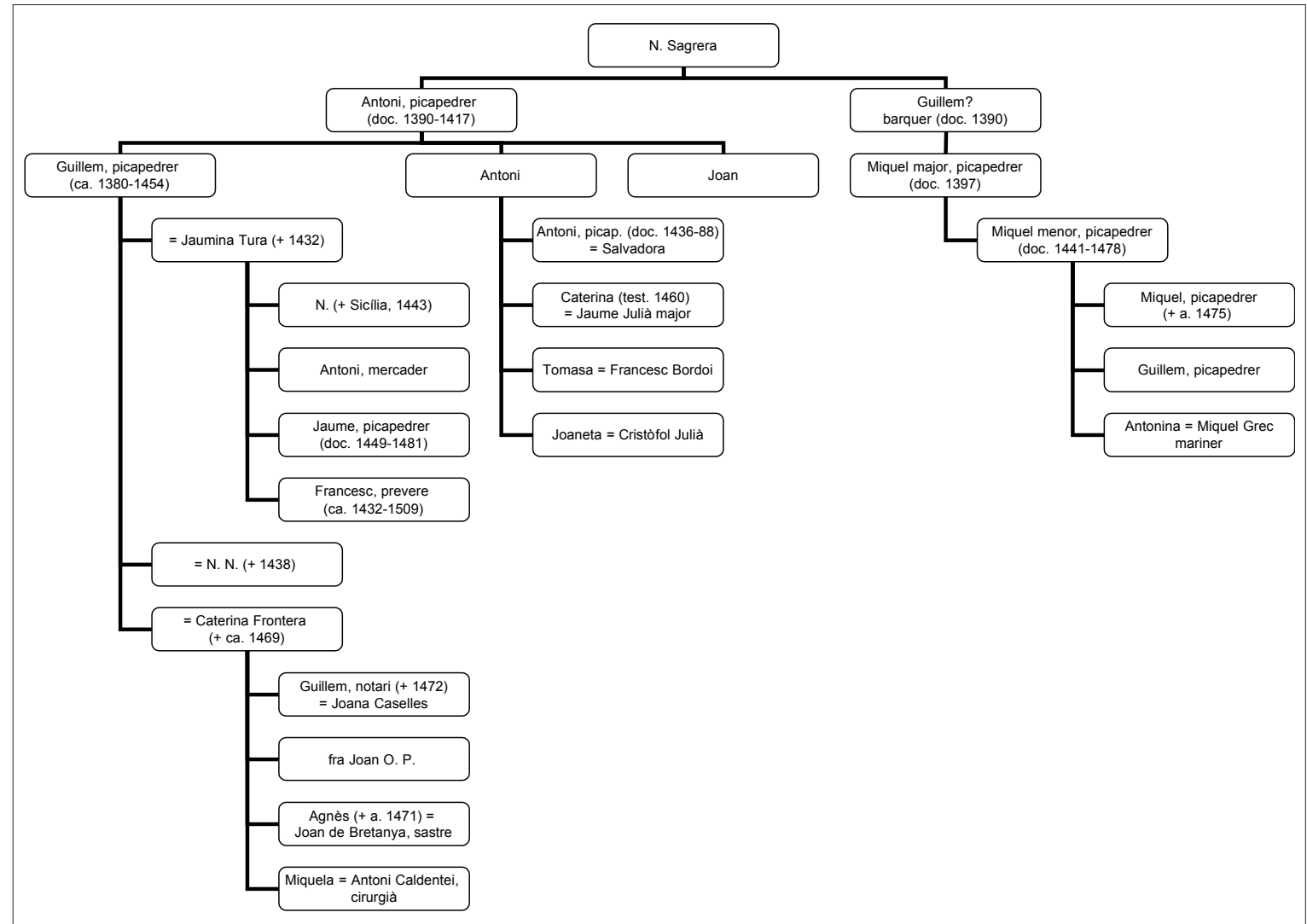

Figura 8.

Genealogia de Guillem Sagrera (quadre elaborat per l'autor).

Aragó i Catalunya ${ }^{112}$. Tres escriptures al·ludeixen a Antoni Gomar, colllaborador del seu germà Francesc en l'obra del cadirat del cor de la seu de Saragossa i principal artífex del de la capella de Santa Bàrbara de Castelnuovo. El 3 d'agost de I453, Antoni, ciutadà de Saragossa i habitant a Nàpols, com a procurador del germà Francesc, signava una àpoca de dotze florins d'or al fuster aragonès Bartomeu Cervera per la devolució d'un préstec. Cinc dies més tard, reconeixia un deute de trenta-vuit ducats a favor de tres col-laboradors en el cor napolità: Miquel Prats, Francesc Torrent i Anequí de Brussel-les ${ }^{113}$. Finalment, el io de maig de l'any següent, juntament amb Egidio de Luna, de la casa del rei, nomenava dos àrbitres per resoldre el plet que els enfrontava. Els altres protocols daten de l'any I452 i afecten Joan Gomar, germà dels anteriors, que hi apareix qualificat de fuster i imaginaire, amb la qual cosa resta definitivament aclarida la seva professió. El ıo de maig nomenava procurador Antoni Salvador, notari de Mallorca, i el 29 de juny actua com a testimoni en la concòrdia pactada - però no se'ns explica el motiu - entre un escultor alemany («Petrus ymaginarius tudiscus») i el fuster Miquel Bell, d'una banda, i els també fusters Enric Saz i Joan de Borbas, de l'altra. Hem de suposar que Joan també treballava en el cadirat de la capella reial napolitana. Un tercer document evoca la procedència catalana de Joan, "partibus Catalonie», probablement de Tarragona. Mentrestant, el i6 de juny, rebia el jurament fet sobre els Evangelis per la seva muller, Joana de Saragossa - divorciada o repudiada, perquè està escrit «que fuí femina vestra»-, la qual declarava davant el notari que el fill Francesc, de devers tres anys, ho era també de Gomar, encara que, per mala voluntat, algunes llengües de foc asseguraven el contrari.

Per acabar, vull afegir un document procedent de l'ACA, que insisteix en un tema molt suggestiu, i que sovint és abordat per la historiografia artística: la circulació d'obres d'art entre Itàlia i els territoris hispans en època del Magnànim. Es tracta d'una carta enviada des de Castelnuovo pel rei al batlle general de València, Berenguer Mercader, el 6 de juny de I449, on s'esmenta un bust florentí que figurava la Verge ${ }^{114}$. Primer havia passat de Florència a València $i$ ara el rei el reclamava per a Nàpols. El breu text també palesa la sensibilitat artística del monarca:

Balle general, aquí és una statua de Nostra Dona de la cintura en sus, la qual nos fou tramesa de Florença e aquella desijam molt haver ací, e per ço vos pregam, encarregam e manam que de continent recbuda la present haiau la da San Leocadio. Entre d'altres, vegeu Adele Condorelli, «El hallazgo de los frescos de Paolo de San Leocadio en la catedral de Valencia y algunas consideraciones acerca de Francesco Pagano", Archivo Español de Arte, 310 (2005), p. 175-179. De la mateixa autora, «El cardenal Rodrigo de Borja, mecenas de Francesco Pagano y Paolo da San Leocadio", dins Els Fills del Senyor Papa. Actes del II Simposi Internacional sobre els Borja. V Centenari de la mort de Cèsar Borja (ValènciaGandia, 2007) (en premsa).

112. ARM, Protocols, 2580. Sobre els Gomar, vegeu almanco R. S. Janke: «The Retable of Don Dalmau de Mur y Cervelló from the Archbishop's Palace at Saragossa: A Documented Work by Francí Gomar and Tomàs Giner", Metropolitan Museum Journal, 18 (1983), p. 65-83 (trad. a Aragonia Sacra, III, 1988, p. 71-90); Francesc FITÉ, «Franci Gomar y el nuevo coro de la Seu Vella de Lleida», dins Actas del Congreso Internacional sobre Gil de Siloe y la Escultura de su época (1999), Burgos, 2001, p. 559-572; I. Companys i N. Montardit, El cadirat de cor de la Seu de Tarragona. Història i iconografia dels medallons, Tarragona, 2000.

113. Aquesta notícia fou publicada per Gabriel LLOMPART, «Miscelánea...», p. 93, n. 30. No coneixem la relació d'aquest Anequí amb els homònims documentats a Navarra (un pintor d'inicis del segle xv, al palau reial d'Olite) i a Toledo (patriarca de la dinastia Egas i, des del 1458, mestre major de la catedral).

114. ACA, Cancelleria, Reg. 2657, f. 233 v. 
115. ACA, Cancelleria, Reg. 2660, f. 16

116. ACA, Cancelleria, Reg. 2720; 1444, 24 d'abril.

117. ACA, Cancelleria, Reg. 2719; 1449, 16 de setembre.

118. ACA, Cancelleria, Reg. 2661, f. 5 i 14. Cfr. C. MarinesCU, «Notes sur le faste à la cour d'Alfonse V, roi de Naples", Mélanges d'Histoire Géneral. Univ. de Cluj, I (1927), p. 133-146. Agraeixo aquesta referència bibliogràfica a Rafael Cornudella.

Sigles. ACA: Arxiu de la Corona d'Aragó. ACB: Arxiu Capitular de Barcelona. ACM: Arxiu Capitular de Mallorca. ADM: Arxiu Diocesà de Mallorca. AHPB: Arxiu Històric de Protocols de Barcelona. ARM: Arxiu del Regne de Mallorca. BSAL: Bolletí de la Societat Arqueològica Lul-liana. dita statua e a aquella façau fer lo stoig necessari per poder venir ben segura e sens perill de trencar o guastar-se e ab la primera fusta segura que vinga la'ns trametau e per res no y metau dilació si'ns desijau servir.

Aquesta finesa és una virtut inalterable de la psicologia del monarca, més ben estudiada pel que fa a la seva bibliofília, però que també es manifesta davant d'uns altres episodis artístics, com ara quan rep dels consellers de Barcelona una imatge d'or de santa Eulàlia i una conca d'argent i els expressa el seu agraïment, «tant per ésser cascuna en sa specie de singular perfecció e bellesa quant encara per ésser coses dignes» ${ }^{115}$, o quan contesta al procurador reial de Mallorca, Llàtzer de Lloscos, l'arribada de sis vànoves «bellíssimas»" ${ }^{116}$, o quan acusa rebut al tresorer general Perot Mercader d'una imatge de la Pietat feta amb marbre «molt bella» ${ }^{117}$, o quan decideix d'adquirir, empès per la insistència del seu comprador oficial, Andreu Pol, una segona tapisseria amb la història del rei Assuer (d'antuvi s'hi negava, perquè ja tenia un tapís amb el mateix argument), «pus tan bells són nos compreu», juntament amb un tapís amb la història de Nabucodonosor, «entès quant dieu ésser bells» ${ }^{118}$. 